University of Rhode Island

DigitalCommons@URI

Open Access Dissertations

2012

\title{
IMPROVING ELECTROLYTES FOR LITHIUM-ION AND LITHIUM OXYGEN BATTERIES
}

Dinesh Chalasani

University of Rhode Island, dinesh.chalasani@gmail.com

Follow this and additional works at: https://digitalcommons.uri.edu/oa_diss

\section{Recommended Citation}

Chalasani, Dinesh, "IMPROVING ELECTROLYTES FOR LITHIUM-ION AND LITHIUM OXYGEN BATTERIES"

(2012). Open Access Dissertations. Paper 96.

https://digitalcommons.uri.edu/oa_diss/96

This Dissertation is brought to you for free and open access by DigitalCommons@URI. It has been accepted for inclusion in Open Access Dissertations by an authorized administrator of DigitalCommons@URI. For more information, please contact digitalcommons-group@uri.edu. 
IMPROVING ELECTROLYTES FOR LITHIUM-ION AND LITHIUM OXYGEN

\section{BATTERIES}

BY

Dinesh Chalasani

A DISSERTATION SUBMITTED IN PARTIAL FULFILLMENT OF THE REQUIREMENTS FOR DOCTOR OF PHILOSOPHY

IN

CHEMISTRY

UNIVERSITY OF RHODE ISLAND

2012 
DOCTOR OF PHILOSOPHY DISSERTATION

OF

Dinesh Chalasani

APPROVED:

Thesis Committee:

Major Professor Brett L. Lucht

William B. Euler

David R. Heskett

Nasser H. Zawia DEAN OF THE GRADUATE SCHOOL

UNIVERSITY OF RHODE ISLAND

2012 


\begin{abstract}
There is an ever increasing demand for fossil fuels. Lithium ion batteries (LIBs) can effectively reduce the production of greenhouse gases and lessen the need for fossil fuels. LIBs also have great potential in electric vehicle applications as an alternative to petroleum modes of transportation. Understanding the chemical reactions between the electrolyte and electrodes in LIBs is very crucial in developing batteries which can work over a wide temperature range and also give a wide potential window. The Solid Electrolyte Interface (SEI), formed by the reduction of solvent molecules on the surface of electrodes, is an important component of LIBs. The SEI is very essential to the performance of LIBs. One electron reduction pathway products of solvent molecules was investigated using lithium-naphthalenide. Methylene ethylene carbonate, a high temperature additive has been synthesized and its performance has been tested at $60^{\circ} \mathrm{C}$.

Lithium-Oxygen batteries have an energy density ten times greater than that of LIBs. However, lithium-oxygen batteries have rechargability problems associated with them. The most common electrolyte used in this type of batteries is $\mathrm{LiPF}_{6}$ in carbonate or ether based solvents. $\mathrm{LiPF}_{6}$ inherently decreases electrolyte stability, since $\mathrm{LiPF}_{6}$ can undergo thermal dissociation into $\mathrm{PF}_{5}$ and $\mathrm{LiF}$. $\mathrm{PF}_{5}$ being a strong Lewis acid, can react with electron rich species. The thermal decomposition reactions of $\mathrm{LiPF}_{6}$ based electrolytes are studied in detail with regard to LIBs. The comprehensive study has been conducted on the thermal degradation of several electrolyte systems in the presence of $\mathrm{Li}_{2} \mathrm{O}_{2}$.
\end{abstract}




\section{ACKNOWLEDGMENTS}

I would like to thank Dr. Brett L. Lucht for all his guidance during my graduate studies at URI. I am grateful to Dr. Lucht for his patience and the scientific knowledge he shared with the group. I am also thankful to Dr. Euler for his advice during all the group meetings which helped a lot in understanding many concepts.

I would like to thank my thesis committee Dr. David R. Heskett, Dr. Sze C.Yang and Dr. Godi Fischer for spending their valuable time in reading this thesis. I would like to thank chemistry department in helping me in preparing for this graduate program.

I would like to thank all my friends Christina, Liu Zhou, Mengquing Xu, Swapnil Dalavi, Ron Donn, Sravanthi, Ajay, Varun and Brandon for their valuable suggestions and helping through all these years.

I would like to thank my family, my parents, my sister and my grandmother who are very encouraging and supporting me all these years.

I would like to thank my wife Kalyani, without her support this couldn't be possible. 


\section{PREFACE}

This dissertation is written in manuscript format. The first chapter is an introduction about lithium ion batteries and lithium oxygen batteries. The second chapter is a manuscript that will be submitted to ECS electrochemistry letters. The third chapter is a manuscript published in The Journal of Power Sources. The fourth chapter is a manuscript that is published in ECS electrochemistry letters. The fifth chapter is a manuscript that is published in the Journal of polymer science A. 


\section{TABLE OF CONTENTS}

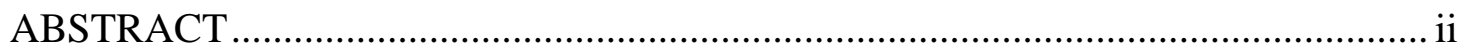

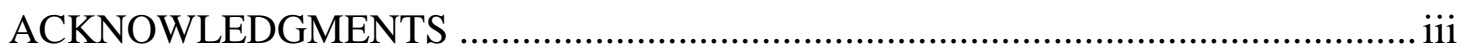

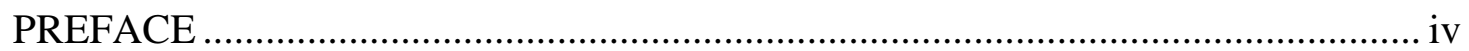

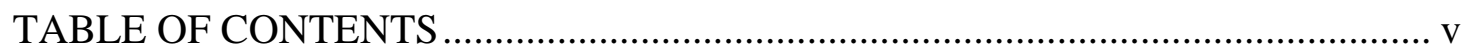

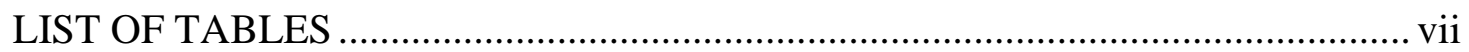

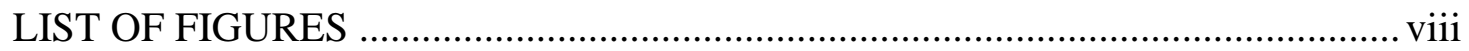

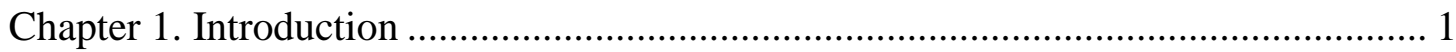

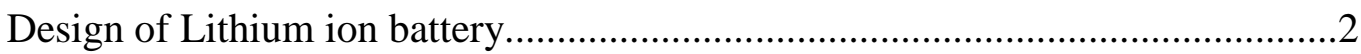

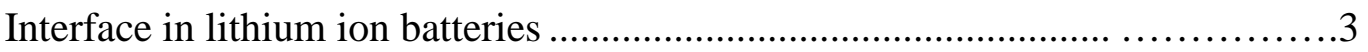

Additives for lithium ion batteries..................................................................

Lithium/oxygen battery..............................................................................

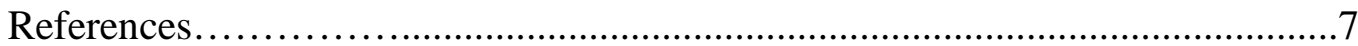

Chapter 2. Reduction products of Solid Electrolyte interface........................13

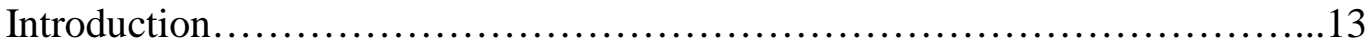

Experimental............................................................

Results and Discussion................................................16

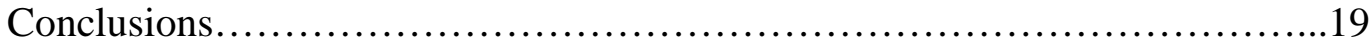

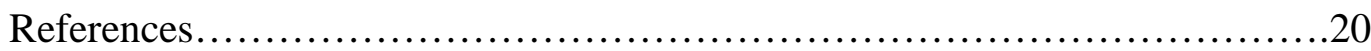

Chapter 3 Methylene ethylene carbonate: Novel additive to improve the High

temperature performance of lithium ion batteries................................28

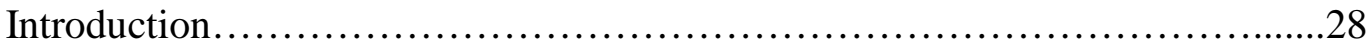


Experimental.

Results and Discussion.................................................

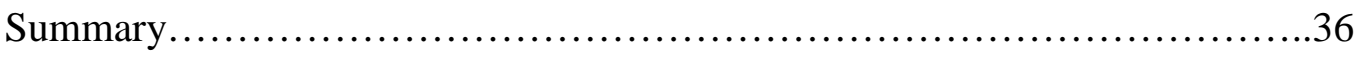

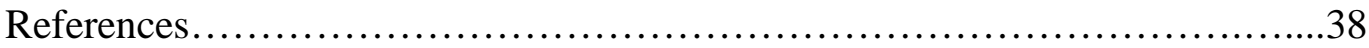

Chapter 4 Reactivity of electrolytes for Lithium-Oxygen Batteries with $\mathrm{Li}_{2} \mathrm{O}_{2} \ldots \ldots .49$

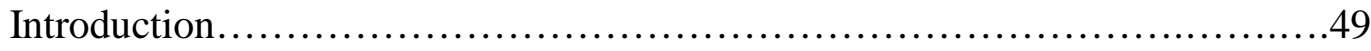

Experimental...................................................50

Results and Discussion.............................................51

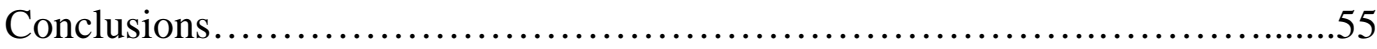

References....................................................... 57

Chapter 5 Two-Step Thermochromism in Poly(3-docosoxy-4-

methylthiophene):Mechanistic Similarity to Poly(3-docosylthiophene).............67

Introduction....................................................67

Experimental.....................................................68

Results and Discussion............................................70

Conclusions............................................................ 73

References...................................................... 74 


\section{LIST OF TABLES}

\section{TABLE}

\section{Chapter 1}

Table 1-1. Physical properties of various organic solvents used in lithium ion batteries.......................................................... 11

II. Chapter 2

Table 2-1. ${ }^{1} \mathrm{H}$ NMR, ${ }^{13} \mathrm{CNMR}$ and GC-MS of the precipitates and gases formed by reaction of Lithium-naphthalenide with various organic carbonates.

III. Chapter 3

Table 3-1. Elemental composition of $\mathrm{C}, \mathrm{F}, \mathrm{O}$ and $\mathrm{P}$ on anodes.....................

Table 3- 2. Elemental composition of $\mathrm{C}, \mathrm{F}, \mathrm{O}, \mathrm{P}$ and $\mathrm{Ni}$ on cathodes............40

IV. Chapter 5

Table 5-1. Summary of measured properties..............................77 


\section{LIST OF FIGURES}

PAGE

\section{Chapter 1.}

Figure 1-1. Schematic diagram of the lithium ion battery discharge process...9

Figure 1-2 Charge and discharge process in $\mathrm{Li} / \mathrm{O}_{2}$ battery..................10

\section{Chapter 2}

Figure 2-1. ${ }^{1} \mathrm{H}$ NMR of the precipitate formed in the reaction between EC and

Lithium naphthalenide.

Figure 2-2. ${ }^{13} \mathrm{C}$ NMR of the precipitate formed in the reaction between EC and Lithium naphthalenide.........................................22

Figure 2-3. ${ }^{1} \mathrm{H}$ NMR of the precipitate formed in the reaction between PC and

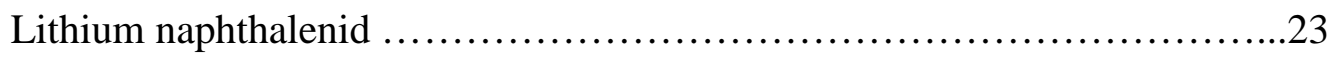

Figure 2-4. ${ }^{13} \mathrm{C}$ NMR of the precipitate formed in the reaction between PC and

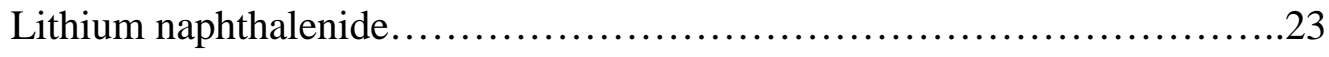

Figure 2-5. ${ }^{1} \mathrm{H}$ NMR of the precipitate formed in the reaction between DEC and Lithium naphthalenide in $\mathrm{D}_{6}$ acetone............................ 24

Figure $2-6{ }^{13} \mathrm{C}$ NMR of the precipitate formed in the reaction between DEC

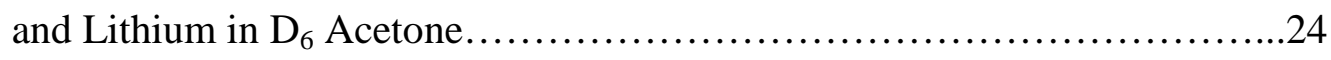


Figure 2-7 ${ }^{1} \mathrm{H}$ NMR of the precipitate formed in the reaction between DMC and Lithium naphthalenide........................................ 25

Figure $2-8 .{ }^{13} \mathrm{C}$ NMR of the precipitate formed in the reaction between DMC

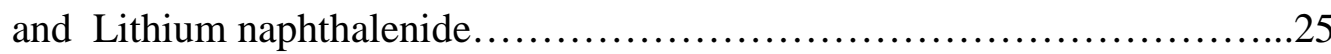

Figure 2-9 FTIR spectra of precipitates formed in reaction of Lithiumnaphthalenide with: (a) Propylene carbonate (b) Ethylene carbonate (c) Diethyl carbonate (d) Dimethyl carbonate.....................................26

\section{Chapter 3}

Figure 3-1. Discharge capacity vs cycle number for $\mathrm{Li}\left[\mathrm{Ni}_{1 / 3} \mathrm{Co}_{1 / 3} \mathrm{Mn}_{1 / 3}\right] \mathrm{O}_{2^{-}}$ based cells containing $1 \mathrm{M} \mathrm{LiPF}_{6}$ in 3:7 EC/EMC with and without added MEC. The cells were cycled at $1 \mathrm{C}$ rate between 3.0 and $4.2 \mathrm{~V}$ at $60{ }^{\circ} \mathrm{C} \ldots . . . .41$

Figure 3-2. XPS spectra of anodes (a)Fresh anode (b) 1MLiPF6 in EC:EMC:DEC(1:1:1) formation cycling; (c)1MLiPF 6 in EC:EMC:DEC(1:1:1) $+2 \%$ additive formation cycling; (d) $1 \mathrm{MLiPF}_{6}$ in EC:EMC:DEC formation cycling and stored at $60^{\circ} \mathrm{C}$ for seven days and cycled at $\mathrm{C} / 5$ rate for 30 cycles; (e) $1 \mathrm{MLiPF}_{6}$ in $\mathrm{EC}: \mathrm{EMC}: \mathrm{DEC}(1: 1: 1)+2 \%$ additive formation cycling and stored at $60^{\circ} \mathrm{C}$ for seven days and cycled a $\mathrm{C} / 5$ rate for 30 cycles

Figure 3-3. XPS spectra of cathodes (a)Fresh cathode (b) 1MLiPF6 in EC:EMC:DEC(1:1:1) formation cycling; (c)1MLiPF 6 in EC:EMC:DEC(1:1:1) $+2 \%$ additive formation cycling; (d) $1 \mathrm{MLiPF}_{6}$ in EC:EMC:DEC formation 
cycling and stored at $60^{\circ} \mathrm{C}$ for seven days and cycled at $\mathrm{C} / 5$ rate for 30 cycles; (e) $1 \mathrm{MLiPF}_{6}$ in $\mathrm{EC}: \mathrm{EMC}: \mathrm{DEC}(1: 1: 1)+2 \%$ additive formation cycling and stored at $60^{\circ} \mathrm{C}$ for seven days and cycled at $\mathrm{C} / 5$ rate for 30 cycles. 43

Figure 3-4 FTIR spectra of anodes (a) fresh anode(b) 1MLiPF6 in EC:EMC:DEC(1:1:1) formation cycling; (c)1MLiPF 6 in EC:EMC:DEC(1:1:1) $+2 \%$ additive formation cycling; (d) ) $1 \mathrm{MLiPF}_{6}$ in EC:EMC:DEC formation cycling and stored at $60^{\circ} \mathrm{C}$ for seven days and cycled at $\mathrm{C} / 5$ rate for 30 cycles; (e) $1 \mathrm{MLiPF}_{6}$ in $\mathrm{EC}: \mathrm{EMC}: \operatorname{DEC}(1: 1: 1)+2 \%$ additive formation cycling and stored at $60^{\circ} \mathrm{C}$ for seven days and cycled a $\mathrm{C} / 5$ rate for 30 cycles............44

Figure 3-5 FTIR spectra of cathodes(a)fresh anode (b) 1MLiPF6 in EC:EMC:DEC(1:1:1) formation cycling; (c)1MLiPF 6 in EC:EMC:DEC(1:1:1) $+2 \%$ additive formation cycling; (d) $1 \mathrm{MLiPF}_{6}$ in EC:EMC:DEC formation cycling and stored at $60^{\circ} \mathrm{C}$ for seven days and cycled at $\mathrm{C} / 5$ rate for 30 cycles; (e) $1 \mathrm{MLiPF}_{6}$ in $\mathrm{EC}: \mathrm{EMC}: \operatorname{DEC}(1: 1: 1)+2 \%$ additive formation cycling and stored at $60^{\circ} \mathrm{C}$ for seven days and cycled a $\mathrm{C} / 5$ rate for 30 cycles............45

Figure 3-6 SEM images of anodes (a) fresh, (b) after formation cycling, (c) after formation cycling with MEC, (d) after cycling and storage, (e) after cycling and storage with MEC .....................................46 
Figure 3-7. SEM images of cathode (a) fresh, (b) after formation cycling, (c) after formation cycling with MEC, (d) after cycling and storage, (e) after

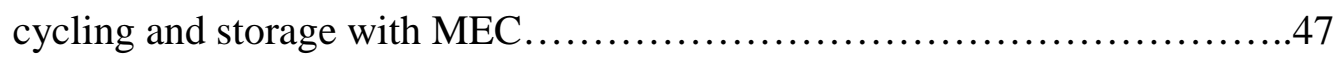

\section{Chapter 4}

Figure 4-1. ${ }^{19} \mathrm{~F}$ NMR (left) and ${ }^{31} \mathrm{P}$ (right) of 0.5 eq $\mathrm{Li}_{2} \mathrm{O}_{2}$ with $1 \mathrm{M} \mathrm{LiPF} 6$ in EC:DMC:DEC stored at $55{ }^{\circ} \mathrm{C}$ for 2 weeks (top) and 20 hours (bottom).....59

Figure 4-2. ${ }^{1} \mathrm{H}$ NMR of 0.5 eq $\mathrm{Li}_{2} \mathrm{O}_{2}$ with $1 \mathrm{M} \mathrm{LiPF}$ in EC:DMC:DEC stored

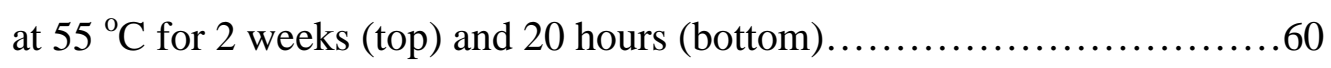

Figure 4-3. ${ }^{19} \mathrm{~F}$ NMR (left) and ${ }^{31} \mathrm{P}$ (right) of 0.5 eq $\mathrm{Li}_{2} \mathrm{O}_{2}$ with $1 \mathrm{M} \mathrm{LiPF} 6$ in ACN stored at $55^{\circ} \mathrm{C}$ for 2 weeks (top) and 20 hours (bottom)...........61

Figure 4-4. ${ }^{1} \mathrm{H}$ (left) and ${ }^{19} \mathrm{~F}$ (right) of 0.5 eq $\mathrm{Li}_{2} \mathrm{O}_{2}$ with $1 \mathrm{M}$ LiTFSI in DME stored at $55{ }^{\circ} \mathrm{C}$ for 2 weeks (top) and 20 hours (bottom)..................62

Figure 4-5. XPS spectra of the precipitate formed by reaction of 0.5 eq $\mathrm{Li}_{2} \mathrm{O}_{2}$

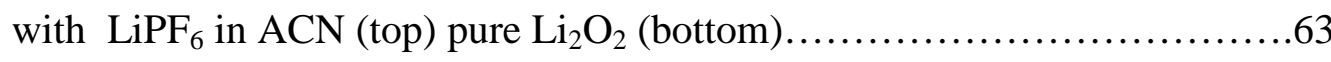

Figure 4-6. XPS spectra of the precipitate formed by reaction of 0.5 eq $\mathrm{Li}_{2} \mathrm{O}_{2}$ with LiTFSI in DME (top), and pure LiTFSI (bottom) .................64

Figure 4- 7. Raman spectra of solid residues from $\mathrm{Li}_{2} \mathrm{O}_{2}$ reaction with various electrolyte systems in comparison with pure $\mathrm{Li}_{2} \mathrm{O}_{2}$ and $\mathrm{Li}_{2} \mathrm{O} \ldots \ldots \ldots \ldots \ldots . \ldots 6$ 


\section{Chapter 5}

Figure 5-1. Reflectance spectra of poly(3-docosoxy-4-methylthiophene). The inset shows the percent reflectance at $600 \mathrm{~nm}$ versus temperature for a sample

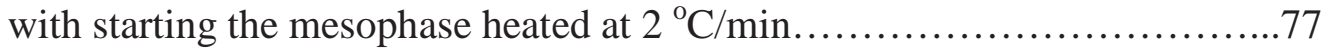

Figure 5-2. Emission intensity at $650 \mathrm{~nm}$ as a function of temperature........78

Figure 5-3. Emission intensity at $650 \mathrm{~nm}$ as a function of temperature.......79

Figure 5-4. DSC thermogram of poly(3-docosoxy-4-methylthiophene) of sample containing mesophase (red dashed line, first heating/cooling cycle) and

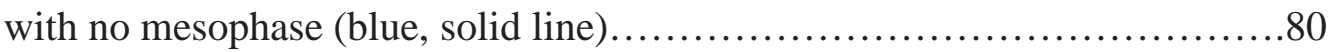

Figure 5-5. Proposed mechanism for the two-step thermochromic transition

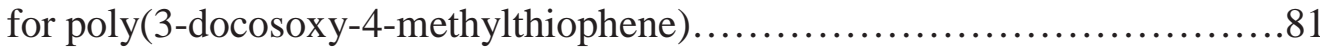




\section{Chapter-1 Introduction}

Battery is an electrochemical devise which converts chemical energy to electric energy. The reduction-oxidation (red-ox) processes that occur in this electrochemical devise are responsible for the conversion of chemical energy to electrical energy. The major components of battery are:

1. Anode is the active material of the battery which gives off electrons to external circuit and gets oxidized.

2. Cathode is the active material that takes the electron from the external circuit and gets reduced.

3. Electrolyte helps in transport of ions from anode to cathode and vice versa during the red-ox process. The electrolyte should be electrically nonconductive but conducts the ions between the electrodes.

4. Separator prevents the direct electrical contact between anode and cathode. The separator should be permeable to electrolyte.

An ideal combination of anode and a cathode is that which can give high voltage and also high energy density. Lithium is the most electropositive metal (-3.04V Vs SHE) and lightest metal (6.94 g/mole) makes it ideal choice as anode material ${ }^{1}$. Thus the lithium batteries (primary) have very high energy densities. The theoretical specific capacity of lithium metal is $3,884 \mathrm{~m} . \mathrm{A} \cdot \mathrm{h} \cdot \mathrm{g}^{-1}$. The rechargeability of such a battery is limited due to dendrite formation which on further cycling leads to the shorting of the cell. These safety issues lead to the development of rechargeable lithium ion batteries. Replacing lithium metal with 
intercalation compounds for lithium ions solves many problems arising due to primary lithium batteries. Lithium-ion batteries are based on such interaction compounds ${ }^{2}$.

\section{Design of Lithium ion battery:}

With the demand for fossil fuels ever increasing the need for alternative energies is getting lot of attention in the scientific community. Lithium ion batteries can provide an alternative solution to petroleum based transportation ${ }^{3}$. A typical rechargeable lithium-ion battery (LIB) consists of a Lithium transition metal oxide cathode and a graphite anode. The lithium transition metal oxide is coated on an aluminum foil which act as current collector and the graphite is coated on copper foil which acts as current collector. The anode and cathode are separated by a thin polyolefin film (polyethylene or polypropylene) separator. The electrolyte used in LIB's is usually a lithium salt (lithium hexafluorophosphate) dissolved in a blend of organic carbonates and esters. Table 1 shows the various solvents used in lithium ion batteries along with their physical properties. This combination of electrodes not only gives wide voltage window but also higher capacities. Typical cathode interaction materials are transition metal oxides like $\mathrm{LiCoO}_{2}$, $\mathrm{LiNi}_{1 / 3} \mathrm{Co}_{1 / 3} \mathrm{Mn}_{1 / 3} \mathrm{O}_{2}, \mathrm{LiMn}_{2} \mathrm{O}_{4}, \mathrm{LiNi}_{0.5} \mathrm{Mn}_{1.5} \mathrm{O}_{4}$ and $\mathrm{LiFePO}_{4}$ etc. A fully lithiated graphite can provide a theoretical specific capacity of $372 \mathrm{mAh} / \mathrm{g}$. At full state of charge graphite can only accommodate one lithium ion per six carbon atoms ${ }^{2}$.

Figure 1 shows the typical construction and discharge process of the lithium-ion battery. Lithium ions are removed from the cathode metal oxide lattice and intercalated in to the anode during the charging process. The transition metal 
undergoes an increase in oxidation state during this process and the reverse process occurs during discharge of the LIB. The LIB is constructed in discharge state so, these batteries have to be charged before any useful electric work can be extracted out of them ${ }^{1}$. Scheme 1 represents the charge discharge reactions that occur in lithium ion battery.

Cathode: $\quad \mathrm{LiMO}_{\mathrm{x}} \underset{\text { Discharging }}{\stackrel{\text { Charging }}{\rightleftarrows}} \quad \mathrm{Li}_{(1-\mathrm{y})} \mathrm{MO}_{\mathrm{x}}+\mathrm{yLi}^{+}+\mathrm{ye}^{-}$

Anode: $\mathrm{C}+\mathrm{yLi}^{+}+\mathrm{ye}^{-} \underset{\text { Discharging }}{\stackrel{\text { Charging }}{\rightleftarrows}} \mathrm{Li}_{\mathrm{y}} \mathrm{C}$

Overall reaction: $\mathrm{LiMO}_{\mathrm{x}}+\mathrm{C} \underset{\text { Discharging }}{\stackrel{\text { Charging }}{\longleftarrow}} \mathrm{Li}_{(1-\mathrm{y})} \mathrm{MO}_{\mathrm{x}}+\mathrm{Li}_{\mathrm{y}} \mathrm{C}$

Scheme-1

\section{Interface in Li-ion batteries}

One of the main reasons behind the cycleability of the present lithium ion battery is the solid electrolyte interface formed during the initial charging of the LIB. The lithiation process, which is insertion of lithium ions in to the graphene structure, occurs at a potential of $\sim 0.2 \mathrm{~V}$ vs. Li. So, during the charging process the potential of the anode is taken very close to the potential of lithium metal. This potential provides a highly reductive environment for the decomposition of electrolyte. Even before any intercalation can occur the electrolyte gets decomposed forming a thin film on the surface of the anode. This thin film is called solid electrolyte interface (SEI). A similar film is formed on the surface of the cathode due to oxidation of the electrolyte. This SEI is very crucial for the performance of the lithium ion battery. The SEI prevents further reduction or oxidation of the 
electrolytes and supports intercalation and deintercalation of lithium ions. The SEI is permeable to lithium ion diffusion but prevents electron tunneling through $\mathrm{it}^{4,5}$. The most commonly used electrolyte system consists of lithium hexafluorophosphate salt dissolved in a blend of ethylene carbonate (EC), dimethyl carbonate (DMC), Propylene carbonate (PC) and diethyl carbonate (DEC). During the early development of LIB PC was tried as the solvent for lithium ion batteries, but PC didn't support interaction of graphite as it cannot form a stable SEI. This was overcome by using EC; the presence of EC supported intercalation by forming a stable SEI ${ }^{4}$.

The chemistry of the SEI has been extensively studied by various research groups. Aurbach et al proposed that the SEI consists of salts of lithium mono and dicarbonates formed by single electron reduction of the solvent molecules as opposed to a two electron reduction pathway ${ }^{7}$. The cyclic carbonates (PC and EC) form dicarbonates of lithium while the linear carbonates (DMC and DEC) form mono carbonates. Chapter 1 in this thesis describes the one electron pathway for the reduction of $\mathrm{PC}, \mathrm{EC}, \mathrm{DEC}$ and DMC.

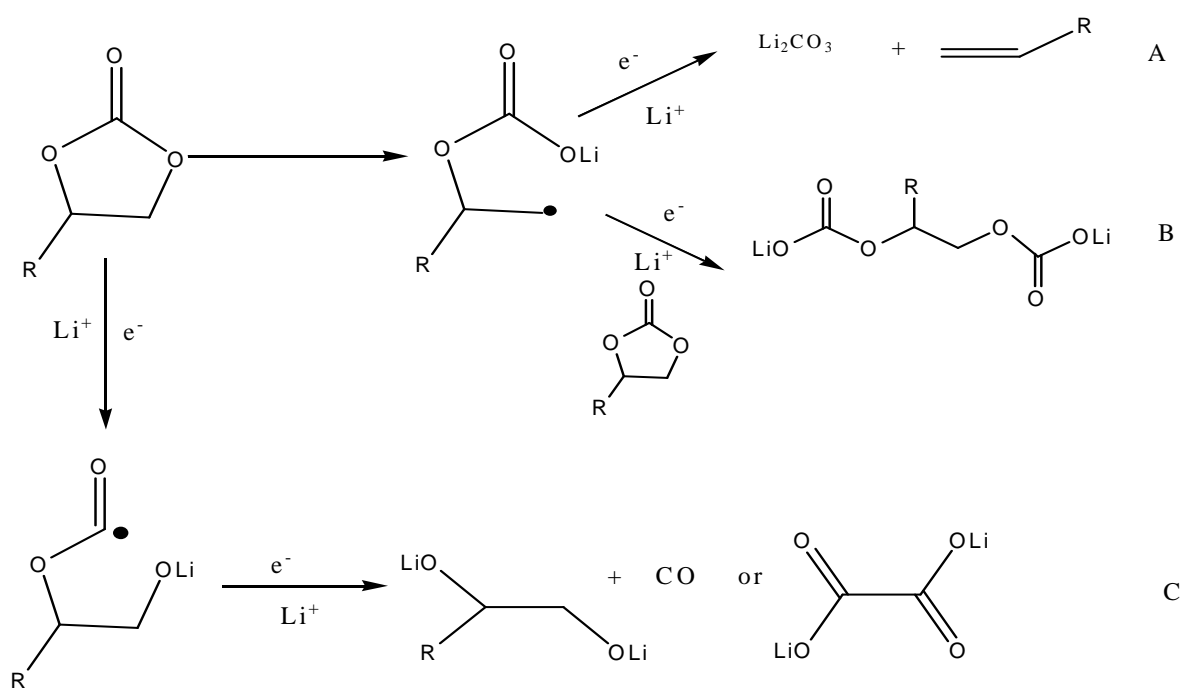


Scheme $2^{6-8}$ Path A represents a two electron reduction of cyclic carbonates, path $\mathrm{B}$ and $\mathrm{C}$ represents one electron reduction of cyclic carbonate.

\section{Additives for Lithium-ion batteries:}

A major requirement for the lithium ion batteries for electric vehicles is long cycle life and also wide temperature window. The SEI formed by the standard electrolyte formulation ( $1 \mathrm{M} \mathrm{LiPF}_{6}$ in 1:1:1 EC:DMC:DEC) is not stable at high temperatures (above $60^{\circ} \mathrm{C}$ ). the ustable SEI can lead to parasitic reaction and accelerate the electrolyte degrardation. This leads to capacity fade in lithium ion batteries. To suppress this capacity fade and improve the cycle life, additives which can form a better SEI are used. Chapter 3 of this thesis deals with one of the additive that is developed by our research group which improved the high temperature performance of LIB.

\section{Lithium/oxygen battery:}

Most of the modern electronic devices have lithium-ion battery. This technology is being used in Hybrid electric vehicle to decrease the demand for fossil fuels ${ }^{10}$. The energy density of lithium ion batteries is dictated by the active material in the electrodes of these batteries. $\mathrm{Li} / \mathrm{O}_{2}$ battery has more energy density than the conventional Li-ion battery ${ }^{10,11}$. The theoretical energy density of $\mathrm{Li} / \mathrm{O}_{2}$ battery is around $11680 \mathrm{Wh} / \mathrm{kg}$, but the current state of rechargeable lithium $/ \mathrm{O}_{2}$ battery is limited to only few cycles ${ }^{1}$. The first rechargeable $\mathrm{Li} / \mathrm{O}_{2}$ battery was invented by Abraham et-al in $1996{ }^{12}$. $\mathrm{Li} / \mathrm{O}_{2}$ battery has lithium anode and a highly porous carbon cathode. Figure 2 shows the discharge process in Li/O2 battery. The anode and cathode reactions in $\mathrm{Li} / \mathrm{O}_{2}$ battery are presented in scheme 4 . 
$\mathrm{Li} \longrightarrow \mathrm{Li}^{+}+\mathrm{e}^{-}$(anode)

$\mathrm{Li}++\mathrm{O}_{2}+2 \mathrm{e}^{-} \longrightarrow \mathrm{Li}_{2} \mathrm{O}_{2}$ (cathode)

$\mathrm{Li}++\mathrm{O}_{2}+4 \mathrm{e}^{-} \longrightarrow 2 \mathrm{Li}_{2} \mathrm{O}$ (cathode)

Scheme 4: Anode and cathode reactions in $\mathrm{Li} / \mathrm{O}_{2}$ battery

During the discharge of lithium-oxygen battery the main products formed on the cathode are Lithium peroxide $\left(\mathrm{Li}_{2} \mathrm{O}_{2}\right)$ and Lithium oxide $\left(\mathrm{Li}_{2} \mathrm{O}\right)$ and during charging the products go back to Li and oxygen ${ }^{12}$. The most common electrolyte used in $\mathrm{Li}-\mathrm{O}_{2}$ batteries is $\mathrm{LiPF}_{6}$ in carbonate or ether based solvents ${ }^{13,14}$. The stability of this electrolyte system in $\mathrm{Li} / \mathrm{O}_{2}$ battery is less since $\mathrm{LiPF}_{6}$ being thermal equilibrium with $\mathrm{PF}_{5}$ and $\mathrm{LiF} . \mathrm{PF}_{5}$ being a strong Lewis acid reacts with electron rich compounds ${ }^{15}$. Lot of the recent work is focused on the insoluble decomposition products formed during the discharge of Li/air battery ${ }^{13,14}$. One of the primary problems is the stability of the electrolyte in the presence of electrode material or reactive intermediate species generated during the reversible charging and discharging of the cell. Chapter 4 of this thesis deals with the stability of various electrolyte formulations in the presence of $\mathrm{Li}_{2} \mathrm{O}_{2}$. 


\section{References:}

1. Hand book of Batteries, D. Linden, McGraw-Hill, New York, 1994.

2. K. Xu, Chem. Rev. 104 (2004) 4304.

3. V. Etacheri. R. Marom, R. Elazari, G. Salitra and Doran Aurbach, Energy Environ. Sci., 4, (2011), 343.

4. R.Fong, U.von Sacken and J. R. Dhan, J.Electrochem. Soc., 1990, 137, 2009

5. E. Peled, J. Electrochem.Soc., 1979, 126, 2047.

6. A.N. Dey and B.P.Sullivan, J.Electrochem. Soc. , 1970 117, 222.

7. D.Aurbach, M. L. Daroux, P.W. Faguy and E. Yeager, J. Electrochem.Soc., 1987, 134, 1611.

8. G. V. Zhuang and P. N. Ross, Electrochem. Solid-state. Lett., 2003, 6, A136.

9. A. Augustsson, M. Herstedt, J.-H. Guo, K. Edstrom, G. V. Zhuang, P. N. Ross, Jr, J.-E. Rubensson and J. Nordgern, Phys. Chem. Chem. Physc., 2004, 6, 4185.

10. Kumar, G.; McCloskey, B.; Luntz, A. C.; Swanson, S.; Wilcke, W.; Journal of Physical Chemistry Letters, 2010, 1, 2193-2203.

11. Kraytsberg, A.; Ein-Eli, Y.; Journal of Power Sources, 2011, 196, 886-893.

12. Abraham, K. A.; Jiang, Z.; Journal of Electrochemical Society, 1996, 143, 1-6.

13. S. A. Freunberger, Y. Chen, Z. Peng, J. M. Griffin, L. J. Hardwick, F. Barde, P. Novak, P. G. Bruce, J. Am. Chem. Soc., 2011, 133, 8040-8047.

14. Freunberger, S. A.; Chen, Y.; Drewett, N.E.; Hardwick, L. J.; Barde, F.; Bruce, P. G.; Angew. Chem. Int. Ed., 2011, 50, 8609-8613. 
15. Christopher, L. C.; Li, W.; Lucht, B. L.; J. Electrochem. Soc. 2005, 152, A2327-A2334. 


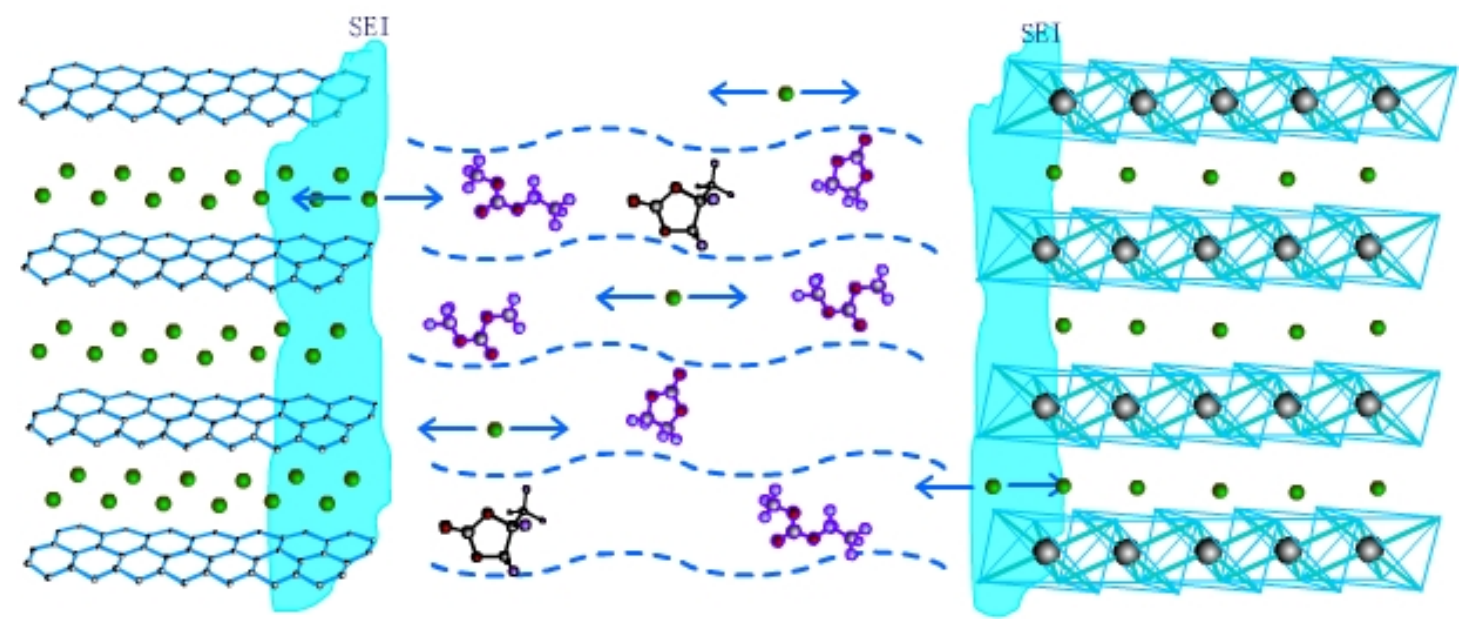

Figure 1-1. Schematic diagram of the lithium ion battery. 

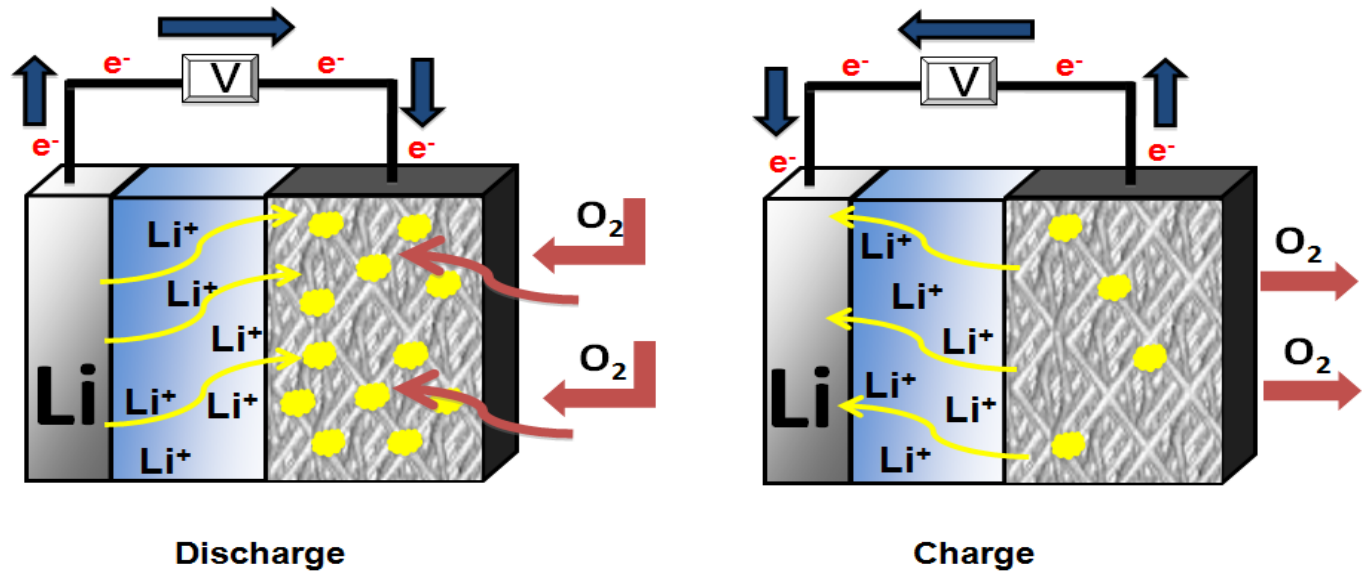

Figure 1-2. Discharge and charge process in $\mathrm{Li} / \mathrm{O}_{2}$ battery 


\begin{tabular}{|c|c|c|c|c|c|}
\hline Solvent & Structure & $T_{m}\left({ }^{\circ} C\right)$ & $\mathrm{T}_{\mathrm{b}}\left({ }^{\circ} \mathrm{C}\right)$ & $\varepsilon\left(25^{\circ} \mathrm{C}\right)$ & $\eta\left(25^{\circ} \mathrm{C}\right)$ \\
\hline $\begin{array}{l}\text { Ethylene } \\
\text { carbonate (EC) }\end{array}$ & & 36.4 & 248 & 89.78 & $\begin{array}{l}1.90 \\
\left(40^{\circ} \mathrm{C}\right)\end{array}$ \\
\hline $\begin{array}{l}\text { Dimethyl } \\
\text { Carbonate (DMC) }\end{array}$ & & 4.6 & 91 & 3.107 & 0.59 \\
\hline $\begin{array}{l}\text { Di ethyl } \\
\text { Carbonate (DEC) }\end{array}$ & & -74.3 & 126 & 2.805 & 0.75 \\
\hline $\begin{array}{l}\text { Ethyl methyl } \\
\text { carbonate (EMC) }\end{array}$ & & -53 & 110 & 2.958 & 0.65 \\
\hline $\begin{array}{l}\text { Propylene } \\
\text { carbonate (PC) }\end{array}$ & & -48.8 & 242 & 64.92 & 2.53 \\
\hline
\end{tabular}

Table 1-1. Physical properties of various organic solvents used in lithium ion batteries 


\section{MANUSCRIPIT- I}

To be submitted to ECS Electrochemistry letters

\section{Reduction products of Solid Electrolyte Interface}

Dinesh Chalasani and Brett L. Lucht.

Department of Chemistry, University of Rhode Island Kingston, RI, USA

Corresponding Author: Dr. Brett L. Lucht.

Department of Chemistry

University of Rhode Island

Pastore Hall, 51 Lower college Rd.

Kingston, RI, 02881, USA.

Phone +1-401-874-5071.

Email address: blucht@chm.uri.edu 


\section{Chapter-2}

\section{Reduction products of Solid Electrolyte interface}

\section{Introduction}

Organic Carbonates are the major solvents used in lithium-ion batteries. The reversibility of the present Lithium-ion battery is mainly attributed to the electrolyte system used in these batteries ${ }^{1}$. Solid electrolyte interface (SEI) is formed by reduction of organic carbonates on the surface of the anode in lithium-ion batteries. The SEI has the properties of the electrolyte which permits only $\mathrm{Li}^{+}$migration into and out of the electrodes but prevents electron tunneling through it ${ }^{2}$. The growth of the SEI at the expense of the electrolyte at high temperatures leads to the capacity fade in lithium-ion batteries. Understanding the reactions that transform these organic carbonates to SEI is essential in developing better lithium-ion batteries. A two electron pathway for the reduction of ethylene carbonate was proposed initially ${ }^{3}$, which was later challenged by Aurbach et. al. 1987. They proposed one electron pathway for the reduction of cyclic carbonates and later extended it to linear carbonates ${ }^{5}$. The major products of one electron reduction are semi carbonates and gases ${ }^{4,5}$. Other than semi carbonates the SEI also consists of lithium oxalates and alkoxides when cycled with carbon based anodes ${ }^{6}$.

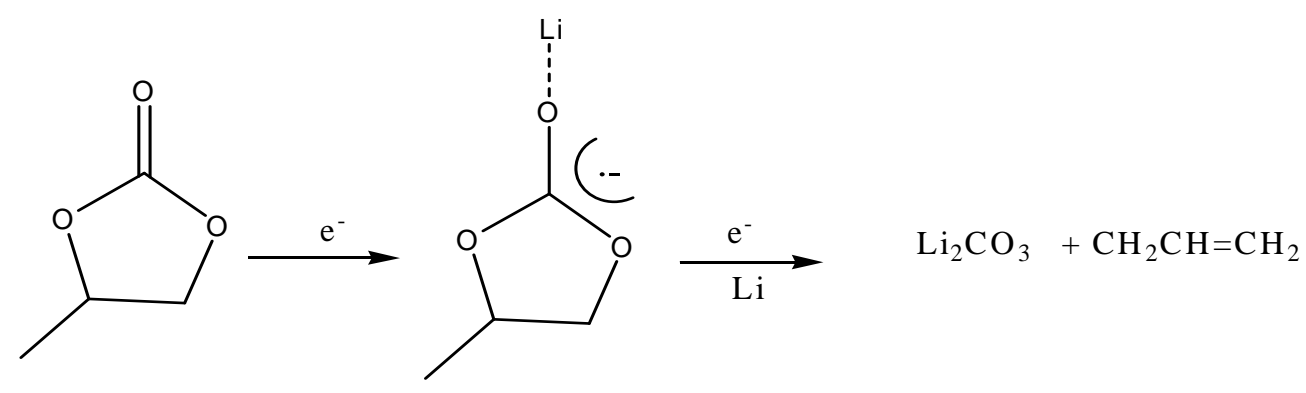

Scheme-1: Two electron reduction of propylene carbonate. 


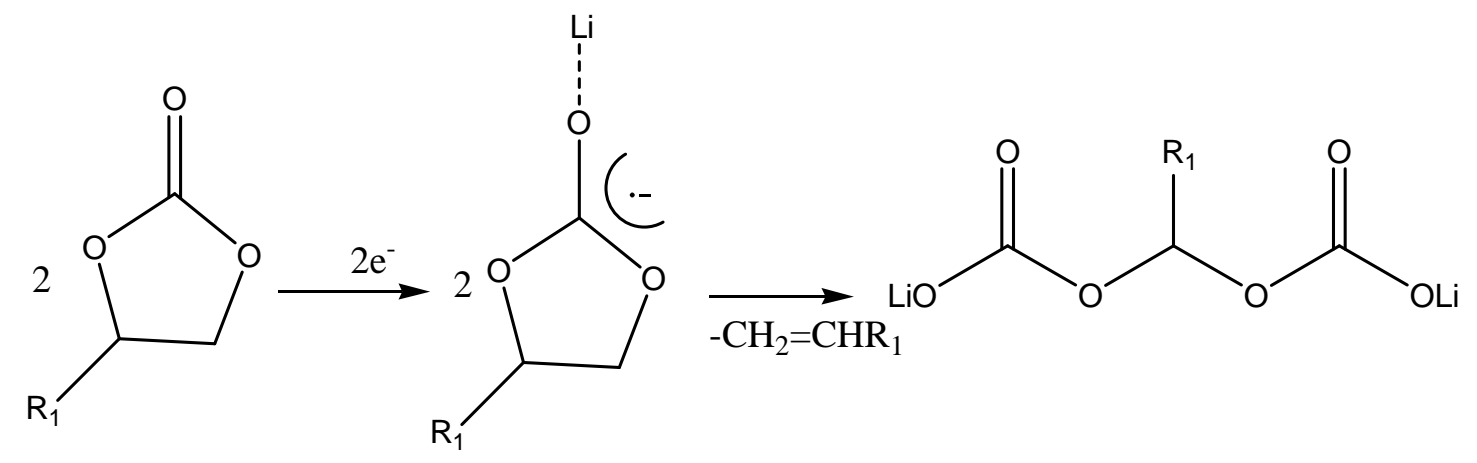

$\mathrm{R}_{1}=\mathrm{H}(\mathrm{EC})$ or $\mathrm{CH}_{3}(\mathrm{PC})$

Scheme-2: Single electron reduction of cyclic carbonates (EC and PC).

Tarascon et. al. analyzed the SEI products formed on the surface of the anode by NMR (nuclear magnetic resonance spectroscopy) and ESI-MS (electron spray ionizationmass spectroscopy). They found that the major products of SEI are semi carbonates along with lithium alkoxides and phosphates ${ }^{8,9}$. In order to understand the structure of the components in the SEI, we used a Lithium napthalenide, a well known one electron transfer agent, as a modle compound for the lithiated graphite surface. Lithium napthalenide is reacted with various carbonate solvents including ethylene carbonate (EC), propylene carbonate (PC), diethyl carbonate (DEC), and dimethyl carbonate (DMC). The products are analyzed by Nuclear magnetic resonance spectroscopy (NMR) and Fourier transform Infrared spectroscopy (FTIR).

\section{Experimental :}

Materials and methods:

All reagents were used without further purification. Reagents and solvents were purchased from either Sigma-Aldrich or Novolyte technologies. Battery grade ethylene carbonate (EC), propylene carbonate (PC), diethyl carbonate (DMC) and 
dimethyl carbonate (DMC) are obtained from Novolyte technologies. All the reactions and purifications are performed in a nitrogen filled glovebox. The analysis of evolved gases during the reaction is performed on Agilent 6890 GC equipped with 5973 mass selective detector and DB-1MS UI column. Helium is used as carrier gas with a flow rate of $1.0 \mathrm{ml} / \mathrm{min}$. The gas samples are analyzed in an isothermal run, the column temperature is maintained at $60^{\circ} \mathrm{C}$ with a run time of six minutes. The mass spectra obtained on these gases are compared with NIST library to determine the molecular structure.

\section{Synthesis of Lithium-Naphthalenide:}

4 grams of Naphthalene $(0.0312$ moles $)$ and $0.197 \mathrm{~g}(0.0283$ moles $)$ of lithium metal are added to a $100 \mathrm{ml}$ round bottom flask containing $50 \mathrm{ml}$ of Tetrahydrfuran (THF). The reaction mixture is stirred over night at room temperature. A dark green color solution of Lithium-naphthalenide is obtained.

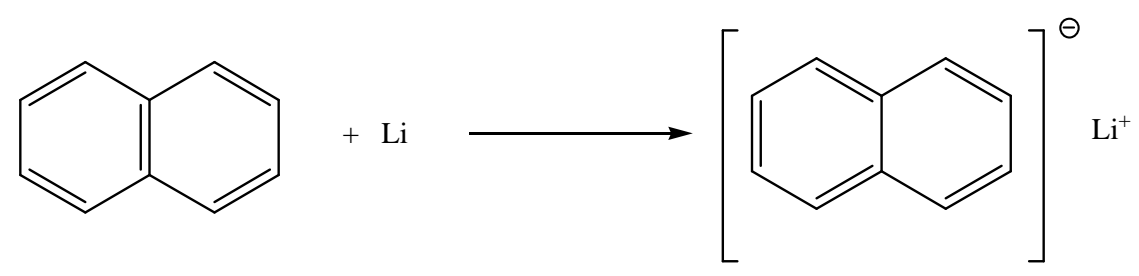

Reaction of Li-naphthalnelide with organic carbonates: To a bottom flasks containing the solution of Li-naphthalenide ( $0.0283 \mathrm{moles}, \sim 25 \mathrm{ml})$ is added ethylene carbonate (EC) in 1:1 mole ratio. All the reaction was stirred over night. Immediately after addition of carbonates to lithium napthalide the solution turns reddish brown and precipitation is observed. The solvent is removed by high vacuum and the resulting 
reddish brown solid is washed with diethyl ether to remove the naphthalene and any residual organic carbonate solvent. The solid is dried under vacuum to remove the solvent. The solids were dissolved in deuterium Oxide $\left(\mathrm{D}_{2} \mathrm{O}\right)$ and ${ }^{1} \mathrm{H}$ and ${ }^{13} \mathrm{C}$ NMR spectra of the solutions were acquired on a Bruker $300 \mathrm{Mz}$ spectrometer. The water peak present as impurity in $\mathrm{D}_{2} \mathrm{O}$ is used for a reference at $4.7 \mathrm{ppm}$ to determine the chemical shifts. Similar reactions were conducted with propylene carbonate (PC), Dimethyl carbonate (DMC) and Diethyl carbonate (DEC). The Fourier transform infrared (FTIR) spectra of the solids were taken in an attenuated total reflection mode on Bruker tensor 27 instrument equipped with germanium crystal. The gas analysis is performed by evacuating the head space of the reaction flask containing $\mathrm{Li}$ naphthalenide in THF followed by carbonate solvent addition. The evolved gases are then sampled using a $10 \mu \mathrm{L}$ GC syringe.

\section{Results and discussion}

\section{NMR analysis of precipitates}

The molecular structures of the precipitates formed in the reaction between lithium naphthalenide and various carbonates are analyzed via a combination of ${ }^{1} \mathrm{H},{ }^{13} \mathrm{C}$ NMR and FTIR. The ${ }^{1} \mathrm{H}$ and ${ }^{13} \mathrm{C}$ NMR spectra of the precipitates show spectral features similar to that of their parent carbonates but have a different chemical shift values. Figure 1 shows the ${ }^{1} \mathrm{H}$ NMR of the precipitates formed by reaction between Lithium naphtahalenide with EC. The ${ }^{1} \mathrm{H}$ NMR shows a singlet around $3.51 \mathrm{ppm}$ which corresponds to methylene protons. Figure 2 contains the corresponding ${ }^{13} \mathrm{C}$ NMR spectrum which contains a singlet at $62.5 \mathrm{ppm}$ and another singlet around $168.3 \mathrm{ppm}$. The singlet around $62.5 \mathrm{ppm}$ is due to methylene carbon $\left(\mathrm{O}-\mathrm{CH}_{2}-\mathrm{CH}_{2}-\mathrm{O}-\right)$ and the 
singlet around 168.3 due to carbonyl carbon. Figure 3 shows the ${ }^{1} \mathrm{H}$ NMR of the precipitate formed by the reaction between Lithium naphthalenide and PC. ${ }^{1} \mathrm{H}$ NMR shows a doublet around $1 \mathrm{ppm}$ due to $-\mathrm{CH}_{3}$ protons coupled to a single proton and multiplet around 3.3ppm which is due to $-\mathrm{CH}_{2}$ type protons. There is another multiplet around $3.7 \mathrm{ppm}$ which is due to the asymmetric proton. This type of splitting pattern is similar to that of PC. Figure 4 shows the ${ }^{13} \mathrm{C}$ NMR of the precipitate formed in the reaction between Lithium naphthalenide and PC which shows four peaks located at 17.7, 66.3, 67.9 and 168.3 which are due to $-\mathrm{CH}_{3},-\mathrm{O}-\mathrm{CH}_{2^{-}},-\mathrm{O}-\mathrm{CH}\left(\mathrm{CH}_{3}\right)$ and $-\mathrm{C}(\mathrm{O})$ - type carbons respectively. Figure 5 shows the ${ }^{1} \mathrm{H}$ NMR of the precipitate formed in reaction between Lithium naphthalenide and DEC which shows a triplet at 1.12 ppm which is due to $\mathrm{CH}_{3}$ protons coupled with $\mathrm{CH}_{2}$ type protons and a quartet at 3.5 ppm due to $\mathrm{CH}_{2}$ protons coupled with $\mathrm{CH}_{3}$ protons. Figure- 6 contains the ${ }^{13} \mathrm{C}$ NMR of the solid isolated from the reaction of lithium naphthalenide with DEC which contains three resonances at $18.73 \mathrm{ppm}, 69.04 \mathrm{ppm}$ and $154.26 \mathrm{ppm}$ which are due to methyl, methylene and carbonyl carbons respectively. Figure-7 contains the ${ }^{1} \mathrm{H}$ NMR spectra of the reaction between Lithium naphtalaneide and DMC. There is single ${ }^{1} \mathrm{H}$ NMR signal at $3.14 \mathrm{ppm}$ is due to $\mathrm{CH}_{3}-\mathrm{O}$ type protons and the corresponding ${ }^{13} \mathrm{C}$ NMR (figure-8) has two signals at 48.7 and 168.59 due to methyl carbon and carbonyl carbon. All the precipitates have trace amount of diethyl ether which is seen in both ${ }^{1} \mathrm{H}$ (t 1.1 and q 3.5 ppm) and ${ }^{13} \mathrm{C}$ NMR (14.7 and $\left.66.4 \mathrm{ppm}\right)$. Table 1 shows all the chemical shifts of the precipitates formed in the reactions. 


\section{FTIR analaysis of precipitates}

Figure 9 contains the FTIR spectra of the precipitates formed in the Lithium naphthalenide reaction with various carbonate solvents. All of the precipitates have similar structural features in the $2000-700 \mathrm{~cm}^{-1}$ region. Absorptions are observed at $1650 \mathrm{~cm}^{-1}, 1350 \mathrm{~cm}^{-1}, 1100 \mathrm{~cm}^{-1}$ and $820 \mathrm{~cm}^{-1}$ for all precipitates. All the precipitates contain asymmetric and symmetric stretching modes around $3000 \mathrm{~cm}^{-1}$ corresponding to alkane or alkene groups present in these precipitates. Asymmetric stretching of carbonate $\mathrm{O}-\mathrm{C}=\mathrm{O}$ groups around $1650 \mathrm{~cm}^{-1}$ and asymmetric stretching mode of $\mathrm{C}-\mathrm{O}$ -C group around $1100 \mathrm{~cm}^{-1}$ are present in all the precipitates. The high intense peaks around $1300 \mathrm{~cm}^{-1}$ to $1400 \mathrm{~cm}^{-1}$ are due to C-O symmetric stretching.

The NMR and FTIR spectral features of the precipitates are identical to the pure compounds previously reported. ${ }^{7}$ The combination of spectral data from both NMR and FTIR indicates that the one electron reduction products of the carbonate solvents used in Li-ion battery are exclusively lithium mono and di alkyl carbonates. By the reduction of cyclic carbonates (EC and PC) the products formed are Lithium ethylene dicarbonate (LEDC) from EC and Lithium propyl dicarbonate from PC. By the reduction of linear carbonates (DMC and DEC) the products are exclusively lithium methyl carbonate and lithium ethyl carbonates respectively.

\section{GC-MS analysis of Gases}

Since gas evolution was observed during the reduction reaction of carbonates with lithium naphthalenide, the gasses evolved during reaction were analyzed by GC-MS. Upon reaction of lithium naphthalenide with EC the reaction mixture evolves gas which matches to the NIST library spectrum of ethylene. Reaction of propylene 
carbonate results in the generation of propylene gas. Analysis of the gases evolved during the reaction of $\mathrm{Li}$ naphthalenide with $\mathrm{DMC}$ and $\mathrm{DEC}$ have not been fully characterized due to interference of Nitrogen and Oxygen gases in GCMS analysis.

\section{Conclusions:}

A model compound Li napthalenide has been used to simulate one electron reduction reaction of organic carbonates. The precipitates of the reactions were analyzed by a combination of NMR and FTIR spectroscopy while the gases evolved during the reaction were analyzed by GCMS. Analysis of the products confirms that the previously reported reactions in Scheme 1 and 2 are the dominant reduction reactions of ethylene carbonate and propylene carbonate. The primary products of the reduction of EC are LEDC and ethylene and the primary reduction products of PC are LPDC and propylene. Analysis of the reduction products of diethyl and dimethyl carbonnate confirm that the primary products are lithium ethylcarbonate and lithium methyl carbonate. Unfortunately, the gasses evolved from these reactions have not been fully characterized and thus the complete reaction cannot be determined. 


\section{References:}

1. Frong, R.; Von Sacken, U.; Dhan, J.R. J.Electrochem.Soc. 1990, 137, 2009

2. Xu, K. Chem. Rev 2004, 104, 4303.

3. A. N. Dey and B. P. Sullivan, J.Electrochem. Soc., 1990. 137, 2009.

4. D. Aurbach, M. L. Daroux, P. W. Faguy and E. Yeager, J. Electrochem. Soc., 1987, 134, 1611.

5. Ein-Eli, Y. Electrochem. Solid-State Lett. 1999, 2, 212

6. G. V. Zhuang and P. N. Ross, Electrochem. Solid-State Lett., 2003,6, A136.

7. Xu, K., G. V. Zhuang, et al. J Phys Chem B 2006 110(15): 7708-7719.

8. Gireaud, L.; Grugeon, S.; Laruelle, S.; Pillard, S.; Tarascon, J.-M, J.Electrochem.Soc. 2005, 152, A850

9. Laruelle, S.; Pilard, S.; Guenot,L.; Grugeon,S.; Tarascona, J. -M, J.Electrochem. Soc 2004, 151 A1209 


\begin{tabular}{|llcl|}
\hline & $1 \mathrm{H} \mathrm{NMR}\left(\mathrm{D}_{2} \mathrm{O}\right)$ & $13 \mathrm{C} \mathrm{NMR}\left(\mathrm{D}_{2} \mathrm{O}\right)$ & Gasanalysis \\
EC & $3.5(\mathrm{~s})$, & $62.5,168.3$ & Ethylene \\
PC & $0.9(\mathrm{~d}), 3.3(\mathrm{~m})$, & $17.7,66.32$, & Propene \\
& $3.7(\mathrm{~m})$ & $67.9,168.3$ & \\
DEC (Duterated acetone) & $1.12(\mathrm{t}), 3.55(\mathrm{q})$ & $154.2,69.04$, & \\
& & 18.73 & \\
DMC & $3.14(\mathrm{~s})$ & $48.7,168.5$ & \\
\hline
\end{tabular}

Table 2-1. ${ }^{1} \mathrm{H}$ NMR, ${ }^{13} \mathrm{CNMR}$ and GC-MS of the precipitates and gases formed by reaction of Lithium-naphthalenide with various organic carbonates. 


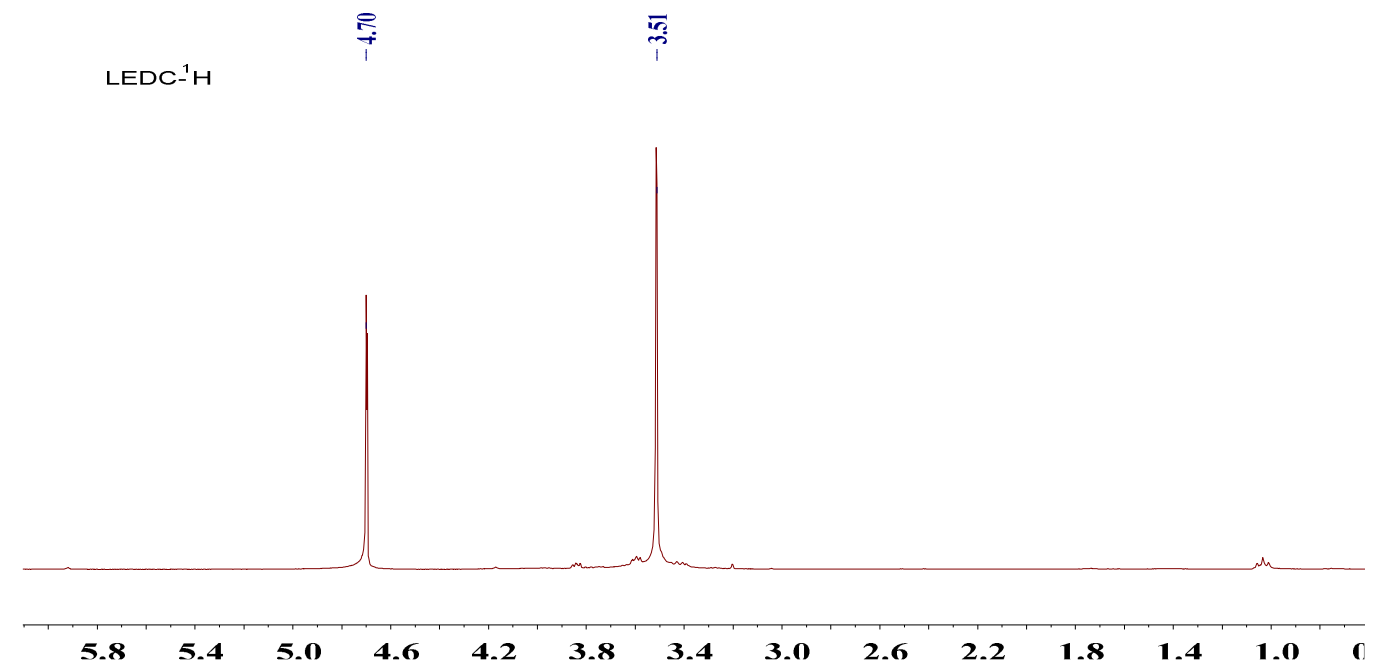

Figure 2-1. ${ }^{1} \mathrm{H}$ NMR of the precipitate formed in the reaction between EC and Lithium naphthalenide.

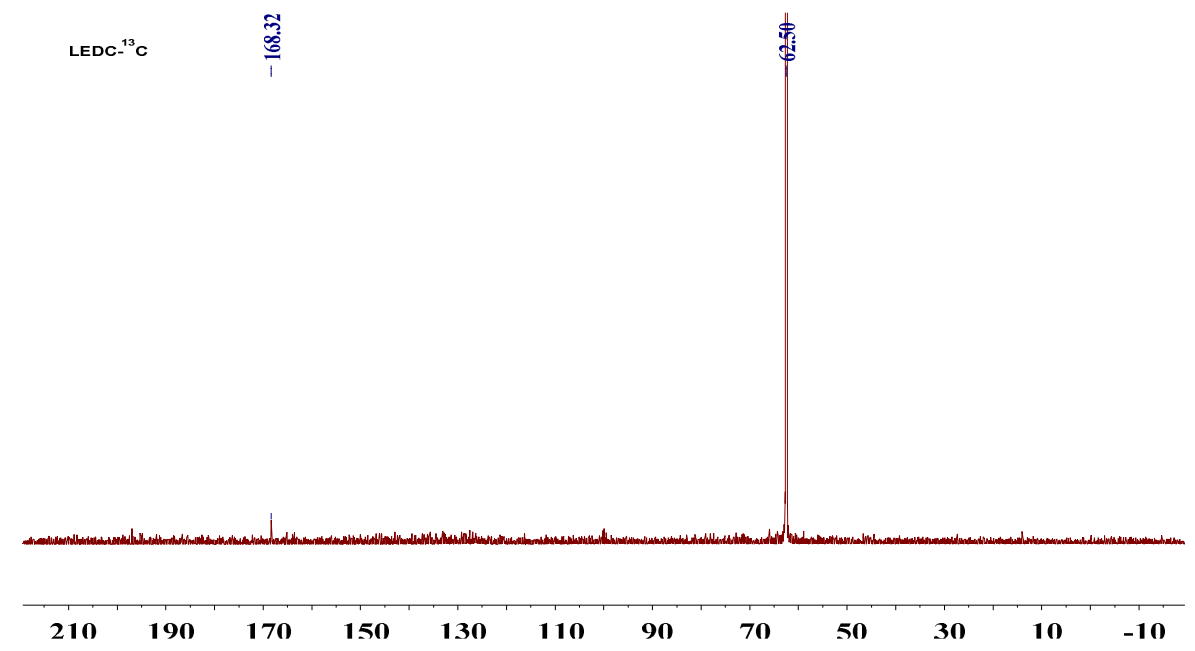

Figure 2-2. ${ }^{13} \mathrm{C}$ NMR of the precipitate formed in reaction between $\mathrm{EC}$ and Lithium naphthalenide. 


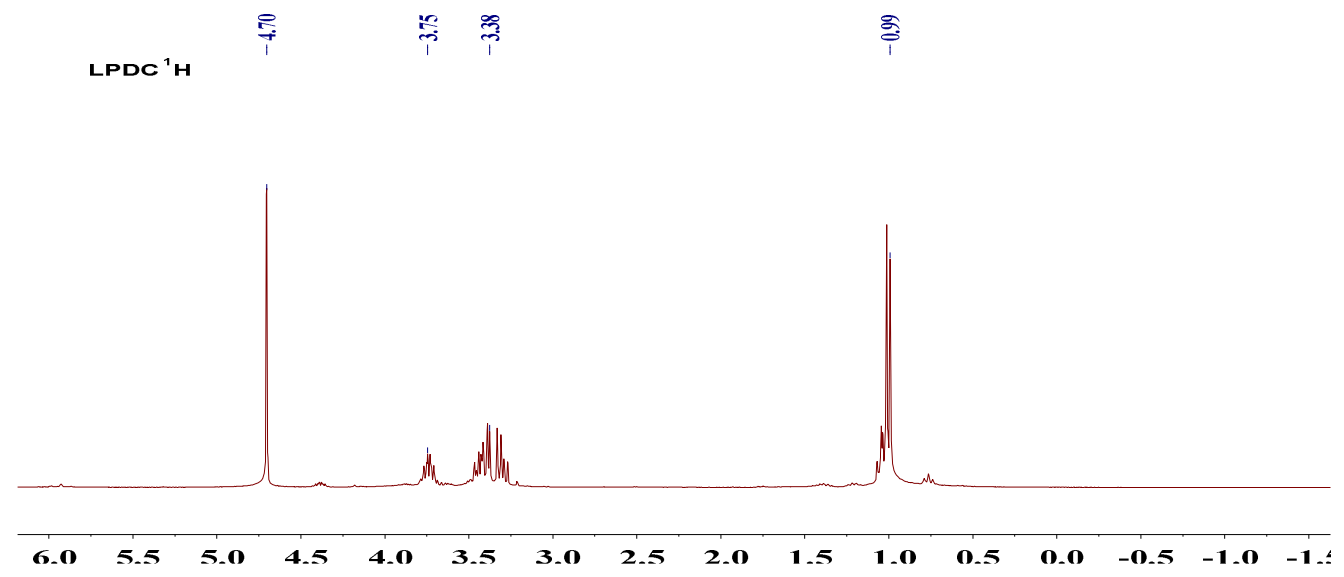

Figure 2-3. ${ }^{1} \mathrm{H}$ NMR of the precipitate formed in the reaction between $\mathrm{PC}$ and Lithium naphthalenide.

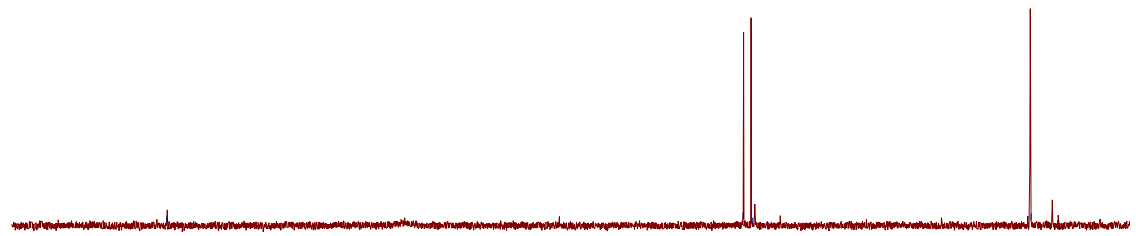

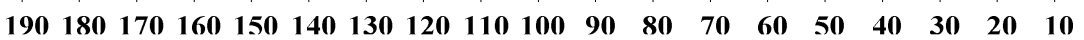

Figure 2-4. ${ }^{13} \mathrm{C}$ NMR of the precipitate formed in the reaction between $\mathrm{PC}$ and Lithium naphthalenide. 


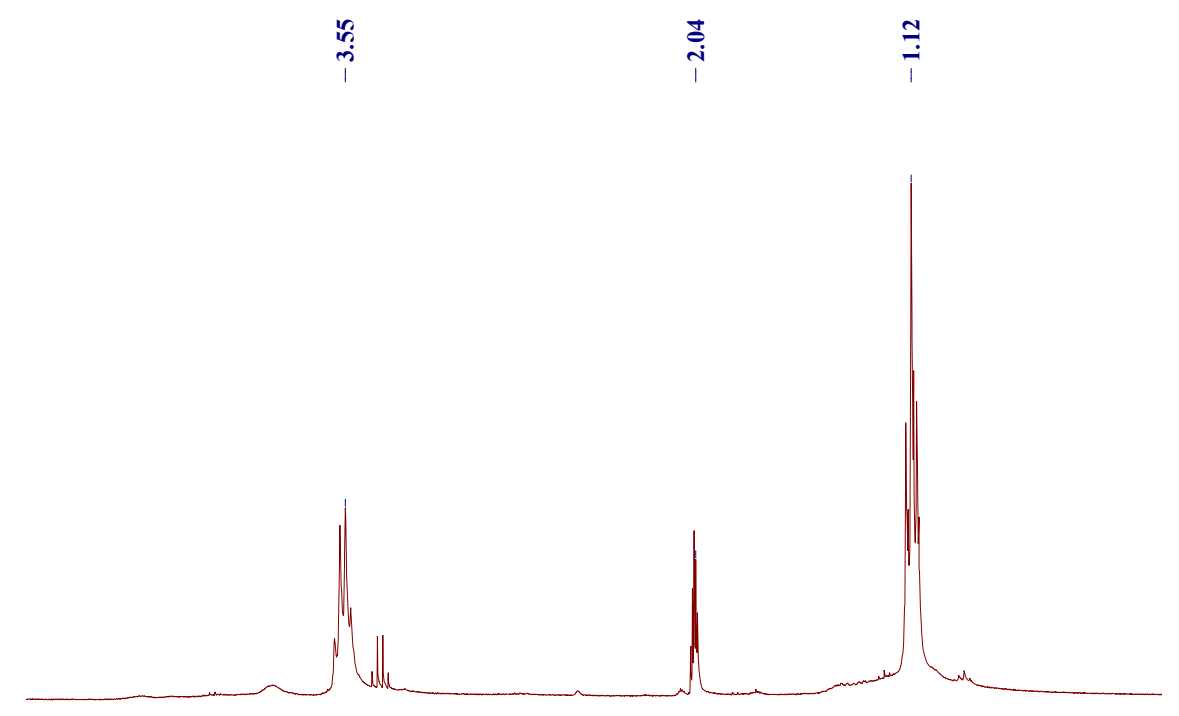

4.8 4.6 4.4 4.2 4.0 3.8 3.6 3.4 3.2 3.0 2.8 2.6 2.4 2.2 2.01 .81 .61 .41 .21 .00 .80 .60 .40 .2

Figure 2-5. ${ }^{1} \mathrm{H}$ NMR of the precipitate formed in the reaction between DEC and Lithium naphthalenide.

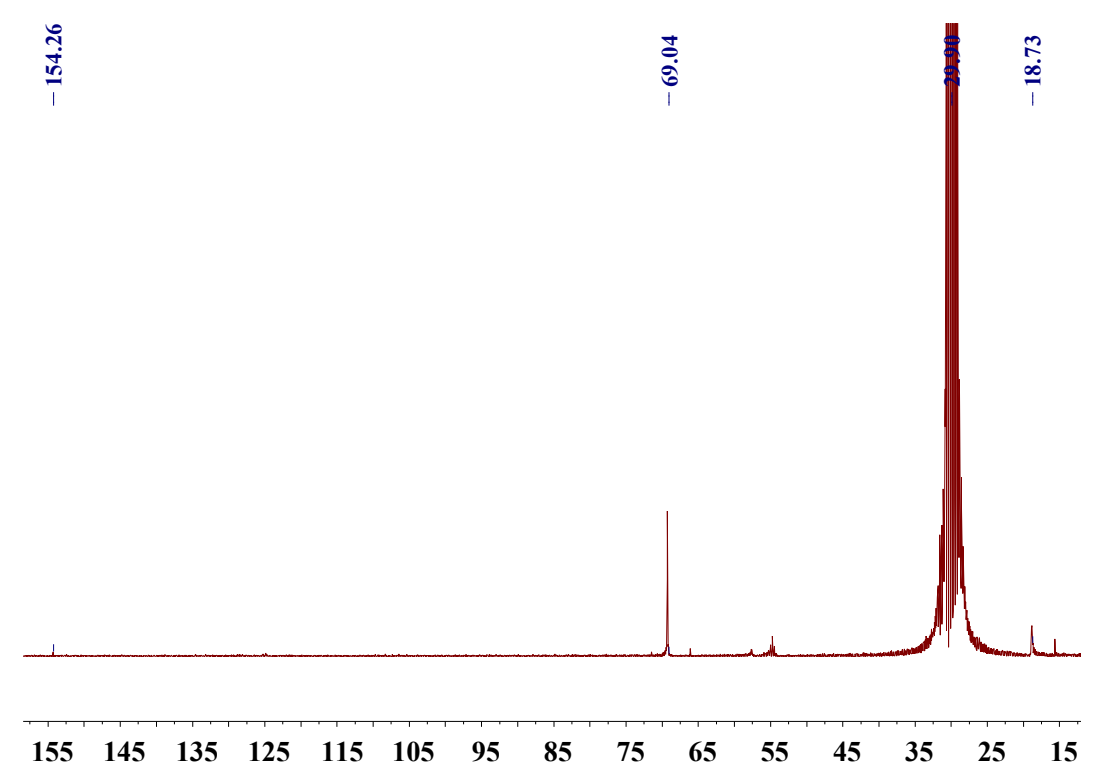

Figure 2-6. ${ }^{13} \mathrm{C}$ NMR of the precipitate formed in the reaction between DEC and Lithium naphthalenide in $\mathrm{D}_{6}$ Acetone. 


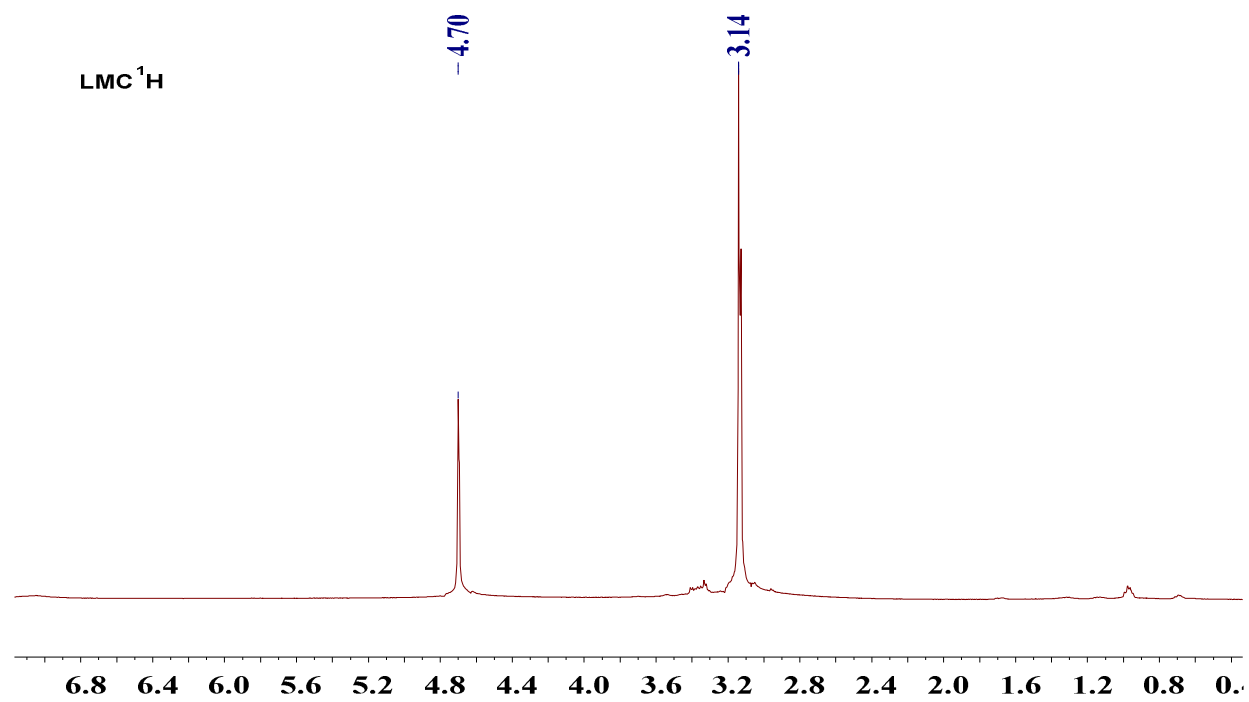

Figure 2-7. ${ }^{1} \mathrm{H}$ NMR of the precipitate formed in the reaction between DMC and Lithium naphthalenide.

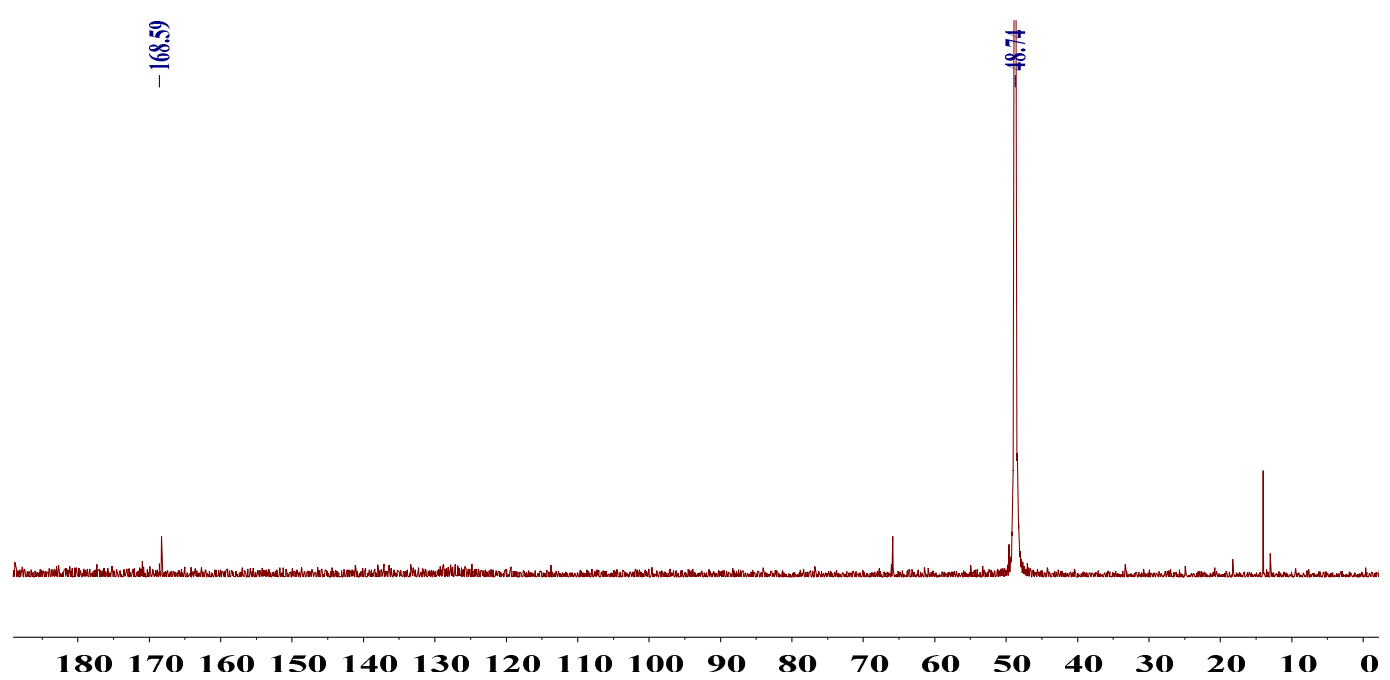

Figure 2-8. ${ }^{13} \mathrm{C}$ NMR of the precipitate formed in the reaction between DMC and Lithium naphthalenide. 


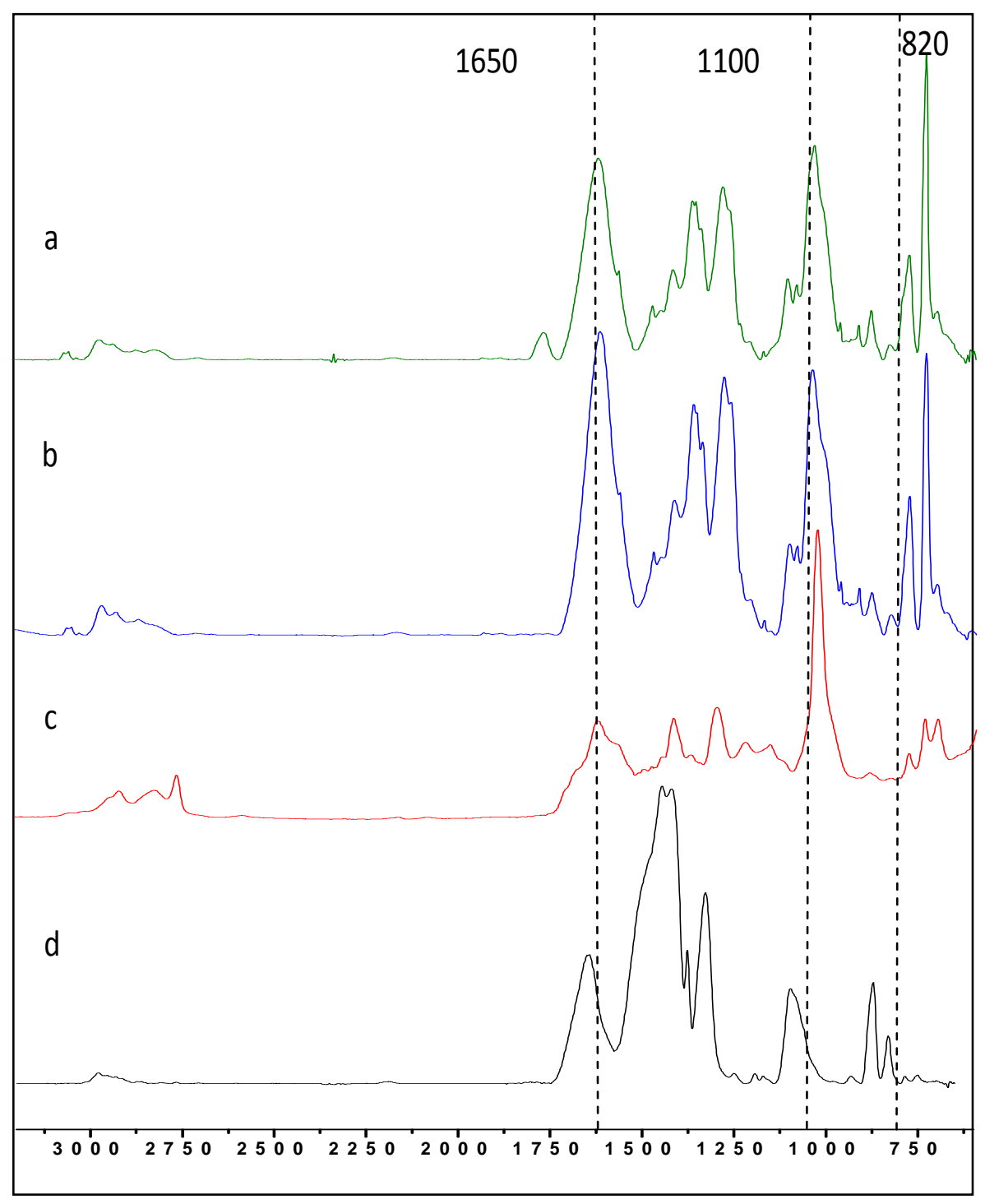

Figure 2-9. FTIR spectra of precipitates obtained by reaction of Lithiumnaphthalenide with: (a) Propylene carbonate (b) Ethylene carbonate (c) Diethyl carbonate (d) Dimethyl carbonate 


\section{MANUSCRIPIT- II}

Published in Journal of Power sources, February 2012

\section{Methylene ethylene carbonate: Novel additive to improve the high}

\section{temperature performance of lithium ion batteries}

Dinesh Chalasani $^{\mathrm{a}}$, Jing Li ${ }^{\mathrm{b}}$, Nicole M. Jackson ${ }^{\mathrm{b}}$, Martin Payne ${ }^{\mathrm{b}}$, Brett

L. Lucht ${ }^{\mathrm{a}}$

a Department of Chemistry, University of Rhode Island, Kingston, RI, USA.

${ }^{\mathrm{b}}$ Novolyte technologies,8001 East Pleasant valley Road, Cleveland, OH 44131 USA.

Corresponding Author: Dr. Brett L. Lucht.

Department of Chemistry

University of Rhode Island

Pastore Hall, 51 Lower college Rd.

Kingston, RI, 02881, USA.

Phone +1-401-874-5071.

Email address: blucht@chm.uri.edu 


\section{Chapter 3 Methylene ethylene carbonate: Novel additive to improve the high temperature performance of lithium ion batteries}

\section{Introduction}

Lithium ion batteries are the dominant secondary battery tech-nology for portable electronic applications and there is great interest in the use of lithium ion batteries in electric vehicle (EV) applications. However, the performance requirements are much more stringent for EV application compared to portable electron-ics applications. EV applications require longer life and greater operational and survival temperature ranges. The more stringent requirements are often limited by the performance of the electrolyte [1]. In particular, the high temperature performance and calendar life are typically limited by the thermal stability of the electrolyte and reactions of the electrolyte with the protective anode solid electrolyte interphase (SEI) [2-4]. One method for improving the calendar life and high temperature stability of lithium ion batteries is the incorporation of additives which are sacrificially reduced on the surface of the anode to generate a more stable anode SEI. The most widely used additive in lithium ion batteries is vinylene carbonate (VC). Incorporation of VC into lithium ion batteries has been reported to improve cycling stability at elevated temperature $(>50$ $\left.{ }^{\circ} \mathrm{C}\right)$ [5-9]. Investigations into the source of performance improvements suggest that VC reacts on the surface of both the graphite anode and metal oxide cathode. However, the generation of poly(alkyl carbonate) on the graphite surface is typically cited as the primary source of performance enhancements. In this manuscript, we report a novel anode SEI film forming additive, methylene ethylene carbonate (MEC) [10,11]. MEC is readily synthesized via a mercury catalyzed cyclization reaction [12]. 
Incorporation of MEC into lithium ion cells results in a signifi-cant improvement in capacity retention upon cycling at elevated temperature $\left(60{ }^{\circ} \mathrm{C}\right)$. Ex situ surface analysis of the electrodes suggests that poly(methylene ethylene carbonate) is generated on the anode and cathode surfaces and is the likely source for performance enhancements. MEC is a promising thermal stabilizing additive for lithium ion batteries.

\section{Experimental}

All of the materials for the synthesis of MEC were purchased from Sigma Aldrich or Acros and used without further purifi-cation. Battery grade ethyl methyl carbonate (EMC), dimethyl carbonate (DMC), diethyl carbonate (DEC), and lithium hexafluorophosphate $\left(\mathrm{LiPF}_{6}\right)$ were provided by Novolyte and used without further purification. MEC is purified by recrystallization and its purity is assessed from ${ }^{1} \mathrm{H}$ and ${ }^{13} \mathrm{C} \mathrm{NMR}$ spectroscopy and gas chromatography. Prismatic cells (650 mAh) containing an artificial graphite anode and a $\mathrm{LiNi}_{1 / 3} \mathrm{Mn}_{1 / 3} \mathrm{Co}_{1 / 3} \mathrm{O}_{2}$ cathode were prepared with $1 \mathrm{M}$ $\mathrm{LiPF}_{6}$ in EC:EMC (3:7 by volume) with and without added MEC. Related lithium ion coin cells are prepared with $1 \mathrm{M}$ LiPF6 in 1:1:1 EC:EMC:DEC with and without 2\% (wt) added MEC. The coin cells used for testing the electrolyte formulations contained $\mathrm{LiNi}_{0 \cdot 8} \mathrm{Co}_{0 \cdot 2} \mathrm{O}_{2}$ ( $\left.\mathrm{LNCO}\right)$ as the active cathode material and mesocarbon microbeads (MCMB) graphite as the active anode material. The coin cells contained $30 \mu \mathrm{L}$ electrolyte and polyethy lene film for a separator and were used for the ex situ surface analysis of the electrodes. The coin cells were cycled with a constant currentconstant voltage charge and a constant current discharge between $4.1 \mathrm{~V}$ and $3.0 \mathrm{~V}$ using a battery cycler (BT-2000 Arbin cycler, College Station, TX). The cells were 
cycled with the following formation procedures: first cycle at $\mathrm{C} / 20$, second and third cycle at $\mathrm{C} / 10$ and remaining two cycles at $\mathrm{C} / 5$. After the initial five formation cycles the cells were cycled at $\mathrm{C} / 5$ rate at room temperature.

The cells were opened in an Ar glove box after cycling and the electrodes were extracted for surface analysis. The electrodes were rinsed with dimethyl carbonate (DMC) three times prior to surface analysis. The XPS spectra were acquired with a PHI 5500 system using Al $\mathrm{K} \alpha$ radiation $(\mathrm{h} v=1486.6 \mathrm{eV})$ under ultra high vac-uum. Characterization of XPS peaks was made by recording XPS spectra for reference compounds, which would be present on the electrode surfaces: $\mathrm{LiF}, \mathrm{Li}_{2} \mathrm{CO}_{3}, \mathrm{Li}_{\mathrm{x}} \mathrm{PO}_{\mathrm{y}} \mathrm{F}_{\mathrm{z}}$ and lithium alkyl carbonate. The graphite peak at $284.3 \mathrm{eV}$ was used as a reference for the final adjustment of the energy scale in the spectra. Lithium was not monitored due to its low inherent sensitivity and small change of binding energy. The spectra obtained were analyzed by Multipak 6.1A software and fitted using XPS peak software (version 4.1). A mixture of Lorentzian and Gaussian functions was used for the least-squares curves fitting procedure. Scanning electron microscopy (SEM) images were taken on a JEOL 5900 scanning electron microscope. Fourier transfer infrared spectroscopy (FTIR) was conducted on a Thermo Scientific Nicolet iS10 Spectrometer with an attenuated total reflection (ATR) accessory. The spectra were acquired with a resolution of $4 \mathrm{~cm}-1$ and a total of 128 scans.

\subsection{Synthesis of t-BOC protected propargyl alcohol (Eq. (1))}

To a solution of propargyl alcohol $20 \mathrm{~g}(0.356 \mathrm{~mol})$ in $30 \mathrm{~mL}$ methylene chloride are added N,N-diisopropylethyl amine $115.0 \mathrm{~g}(0.89 \mathrm{~mol})$ and dimethyl amino pyridine $4.34 \mathrm{~g}(0.0356 \mathrm{~mol})$ at room temperature under nitrogen. The contents are stirred in an 
ice bath while di-t-butyl dicarbonate $100 \mathrm{~g}(0.462 \mathrm{~mol})$ is slowly added under nitrogen purge. The reaction mixture is allowed to stir for $3 \mathrm{~h}$ as the ice bath warms to room temperature. The reaction mixture is then washed with water, $10 \% \mathrm{HCl}$ solution, $10 \%$ NaHCO3 solution, and $\mathrm{NaCl}$ solution $(150 \mathrm{~mL}$ each) followed by drying with magnesium sulfate. The residual solvent is removed via rotary evaporation to yield the t-BOC propargyl alcohol (52.8 g, 95\% yield).

2.2. Synthesis of MEC (Eq. (1)): 1 A suspension of mercury (II) triflate $6.36 \mathrm{~g} \mathrm{(12.7}$ mmol) and tetra methyl urea $4.44 \mathrm{~g}(38.07 \mathrm{mmol})$ in $150 \mathrm{~mL}$ methylene chloride is stirred for $30 \mathrm{~min}$ in a round bottom flask in a nitrogen filled glove box. To that suspension is added t-BOC propargyl alcohol $40 \mathrm{~g}(0.256 \mathrm{~mol})$ and stirred over night. The contents are filtered through silica gel to remove the mercury salts and tetra methyl urea. The residual solvent is removed via rotary evaporation followed by recrystallization in pentane to yield MEC ( $11.5 \mathrm{~g}, 45 \%$ yield). The purity of MEC as estimated by NMR spectroscopy is $>99 \%$. ${ }^{1} \mathrm{H}$ NMR $\left(300 \mathrm{MHz}, \mathrm{CDCl}_{3}\right) \delta 4.95(\mathrm{t}, 2 \mathrm{H})$, $4.79(\mathrm{~m}, 1 \mathrm{H}), 4.38(\mathrm{~m}, 1 \mathrm{H}) .{ }^{13} \mathrm{C}$ NMR $(75 \mathrm{MHz}, \mathrm{CDCl} 3) \delta 152.83,148.93,67.60$, 87.00. Melting point: $31-33{ }^{\circ} \mathrm{C}$.
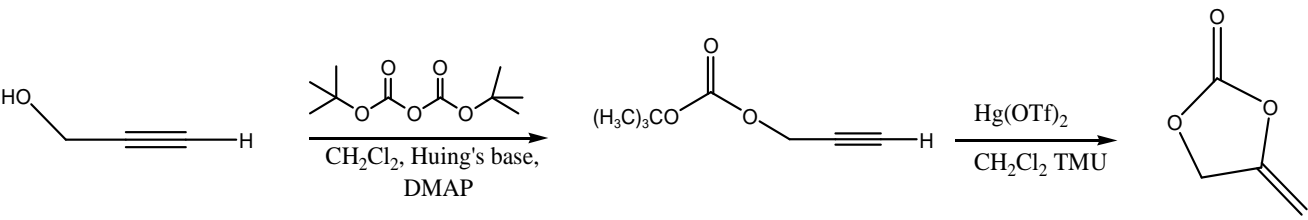

\section{Results and discussion}

Electrochemical testing on full cells The performance of MEC as a thermal stabilizing additive in full cells was examined in $650 \mathrm{mAh}$ prismatic cells containing an artificial 
graphite anode, $\mathrm{LiNi}_{1 / 3} \mathrm{Mn}_{1 / 3} \mathrm{Co}_{1 / 3} \mathrm{O}_{2}$ cathode, and $1 \mathrm{M} \mathrm{LiPF}_{6}$ electrolyte in EC:EMC (3:7 by volume) with and without added MEC. After typical cell formation cycling at room temperature, the cells were cycled at a $1 \mathrm{C}$ rate between 3.0 and $4.2 \mathrm{~V}$ at $60{ }^{\circ} \mathrm{C}$ to simulate accelerated aging (Fig. 1). Cells containing 1 or $2 \%$ of MEC have outstanding capacity retention $(\sim 80 \%)$ after 270 cycles at $60{ }^{\circ} \mathrm{C}$. Comparable cells containing standard electrolyte failed after less than 100 cycles at $60{ }^{\circ} \mathrm{C}$. In order to better understand the source of the performance enhancement by MEC, related coin cells were cycled and ex situ analysis of the electrodes was conducted. The cycling performance of the coin cells after thermal storage was similar to that observed for the accelerated aging experiments on the $650 \mathrm{mAh}$ cells.

\section{Surface analysis}

The surfaces of three sets of electrodes were analyzed by X-ray photo electron spectroscopy (XPS), scanning electron microscopy (SEM), and infra-red spectroscopy with attenuated total reflectance (IR-ATR). The electrode samples were: fresh uncycled electrodes, electrodes after five formation cycles, and electrodes from cells with 30 cycles that were further stored at $60{ }^{\circ} \mathrm{C}$ for one week to simulate accelerated aging. The cells were dismantled at a full state of charge in an argon glove box and the anodes and cathodes were extracted. The electrodes were washed with DMC and dried under vacuum.

\section{XPS analysis}

The electrodes were analyzed by XPS. Figs. 2 and 3 contain XPS spectra of the anodes and cathodes while the elemental concentrations are summarized in Tables 1 and 2. Analysis of the anode surface reveals that the concentration of carbon is 
decreased and the concentration of oxygen is increased after cycling for both the standard electrolyte and the electrolyte with added MEC consistent with the formation of a solid electrolyte interphase (SEI). Anodes extracted from cells after formation cycling with the standard electrolyte have slightly lower concentrations of carbon and oxygen and a higher concentration of fluorine than the anodes extracted after formation cycling with the electrolyte containing MEC. The concentration of phosphorus is low for both cycled anodes. After additional cycling and storage at 60 ${ }^{\circ} \mathrm{C}$ there are only small changes to the elemental concentration of the surface. The higher concentrations of $\mathrm{C}$ and $\mathrm{O}$ and lower concentration of $\mathrm{F}$ on the surface of the anode is consistent with a thicker anode SEI covering more of the electrode surface and the PVDF binder. The C1s spectra of fresh anodes contain peaks characteristic of graphite $(284.3 \mathrm{eV})$ and PVDF (285.5 and $290.3 \mathrm{eV})$. The correspond-ing peak characteristic of PVDF is observed in the F1s spectrum $(687.8 \mathrm{eV})$ while the $\mathrm{O} 1 \mathrm{~s}$ spectrum contains a weak peak attributed to graphite surface oxidation $(\sim 532 \mathrm{eV})$. Significant changes are observed on the electrode surface by XPS after formation cycling. The anode extracted from the cell cycled with standard electrolyte contains new peaks in the $\mathrm{C} 1 \mathrm{~s}$ spectrum consistent with the formation of $\mathrm{C}=\mathrm{O}(288.2 \mathrm{eV})$ and $\mathrm{C}-\mathrm{O}(289.5 \mathrm{eV})$ containing species such as lithium alkyl carbonates, lithium alkoxides, and ethers, as previously reported on the anode SEI [8]. In addition, there is a small peak $(282.9 \mathrm{eV})$ characteristic of $\mathrm{LiC}_{\mathrm{x}}$. The $\mathrm{F} 1 \mathrm{~s}$ spectrum contains peaks characteristic of PVDF $(687.8 \mathrm{eV})$ and $\mathrm{LiF}(684.5 \mathrm{eV})$. A weak P2p signal is observed for $\mathrm{Li}_{\mathrm{x}} \mathrm{PF}_{\mathrm{y}} \mathrm{O}_{\mathrm{z}}(133.7 \mathrm{eV})$ while the corresponding $\mathrm{F} 1 \mathrm{~s}$ peak $(687 \mathrm{eV})$ is similar in binding energy to PVDF. The O1s spectrum contains peaks characteristic of C-O and 
$\mathrm{C}=\mathrm{O}$, consistent with the $\mathrm{C} 1 \mathrm{~s}$ spectra. Anodes extracted from cells containing MEC after formation cycling have similar XPS spectra to the anodes cycled with standard electrolyte. However, the relative intensity of the peak characteristic of LiF is slightly lower. XPS spectra of the anodes extracted from cells cycled and stored at $60{ }^{\circ} \mathrm{C}$ for both electrolytes are similar to the XPS spectra of the anodes after formation cycling suggesting only small changes to the structure of the surface species occur upon aging. The changes to the cathode surfaces upon cycling were smaller than those observed for the anode surfaces cycled in the presence of standard electrolyte. Analysis of the cathode surfaces after for-mation cycling with the standard electrolyte suggest very small changes to the concentrations of $\mathrm{C}, \mathrm{F}, \mathrm{O}$, and Ni. More significant changes were observed for the electrolyte containing MEC. The concentrations of $\mathrm{C}$ and $\mathrm{O}$ are increased while the concentrations of $\mathrm{F}$ and $\mathrm{Ni}$ are decreased. This is consistent with the generation of a cathode surface film in the presence of MEC. The elemental concentrations of the cathode surface in both the standard electrolyte and the electrolyte containing MEC do not change significantly upon aging suggesting only small changes to the surface species. The $\mathrm{C} 1 \mathrm{~s}$ spectrum of the fresh cathode contains peaks characteristic of graphite $(284.3 \mathrm{eV})$ and PVDF (285.5 and $290.3 \mathrm{eV})$. The F1s spectrum contains the corresponding PVDF peak $(687.8 \mathrm{eV})$. The O1s spectrum contains peaks characteristic of metal oxide $(528 \mathrm{eV})$ and residual lithium carbonate $(531 \mathrm{eV})$. The cathodes extracted from cells containing standard electrolyte have only small changes after formation cycling. A new small peak characteristic of $\mathrm{LiF}$ is observed $(684.5 \mathrm{eV})$ in the $\mathrm{F} 1 \mathrm{~s}$ spectrum and the peak in the $\mathrm{O} 1 \mathrm{~s}$ spectrum characteristic of metal oxide $(528 \mathrm{eV})$ has decreased intensity. The changes to the 
surface of the cathode extracted from the cell cycled with electrolyte containing MEC after formation cycles are greater than those observed for the standard electrolyte. New peaks characteristic of $\mathrm{C}-\mathrm{O}$ containing species including ethers and carbonates are observed $(287.5 \mathrm{eV})$ in the $\mathrm{C} 1 \mathrm{~s}$ spectrum and $(534 \mathrm{eV})$ in the $\mathrm{O} 1 \mathrm{~s}$ spectrum. In addition, the peak characteristic of metal oxide $(528 \mathrm{eV})$ is no longer observable suggesting the presence of a relatively thick cathode surface film. Additional cycling and storage at $60{ }^{\circ} \mathrm{C}$ results in changes to the surface of the cathode extracted from the cell containing standard electrolyte. Peaks characteristic of $\mathrm{C}-\mathrm{O}$ and $\mathrm{C}=\mathrm{O}$ containing species are observed in the $\mathrm{C} 1 \mathrm{~s}$ and $\mathrm{O} 1 \mathrm{~s}$ spectra consistent with the formation of lithium alkyl carbonates. The peak of $\mathrm{LiF}$ has a slight increase in intensity while the peak of the metal oxide is no longer detectable. In addition, a new peak $(136 \mathrm{eV})$ in the P2p spectrum is observed consistent with the presence of $\mathrm{Li}_{\mathrm{x}} \mathrm{PF}_{\mathrm{y}} \mathrm{O}_{\mathrm{z}}$. Additional cycling and storage at $60{ }^{\circ} \mathrm{C}$ results in only small changes to the surface of the cathode cycled in the presence of MEC containing electrolyte. A small peak characteristic of $\mathrm{Li}_{x} \mathrm{PF}_{y} \mathrm{O}_{z}$ is observed in the $\mathrm{P} 2 \mathrm{p}$ spectrum.

\section{FTIR analysis}

The IR spectra of both the anodes and cathodes are dominated by peaks from PVDF binder at 1400, 1170, 1070, 877, and $840 \mathrm{~cm}^{-1}$ (Fig. 4). The anodes extracted from cells containing standard electrolyte contain a new peak at $1600 \mathrm{~cm}^{-1}$ consistent with the presence of oxalates or lithium alkyl carbonates. The anodes of cells cycled with MEC contain the peak characteristic of oxalates and lithium alkyl carbonates along with an additional peak at $1750 \mathrm{~cm}^{-1}$ which is characteristic of polycarbonates. The cathodes extracted from cells containing the standard electrolyte have no new 
absorptions (Fig. 5). However, the cathodes extracted from cells cycled with MEC containing electrolyte have an additional peak at $\sim 1800 \mathrm{~cm}^{-1}$ consistent with the presence of polycarbonates.

\section{SEM analysis}

SEM analysis of the fresh anode materials reveal MCMB particles ranging in size from 0.5 to $5 \mu \mathrm{m}$ diameter (Fig. 6). After formation cycling the surface of the MCMB particles appears to be coated with a surface film for both the standard electrolyte and the electrolyte containing MEC. The appearance of this surface film is similar for both electrolytes. SEM images of the anodes after thermal storage and cycling appear to have additional surface film coverage for both the standard and MEC containing electrolytes. However, the surface films appear similar for both electrolytes. SEM analysis of the cath-odes before cycling, after formation cycling, and after storage at elevated temperature with cycling are very similar suggesting that any surface films on the cycled cathodes are very thin (Fig. 7).

\section{Summary}

A novel anode SEI film forming additive, methylene ethylene carbonate (MEC), has been reported. MEC is prepared in good yield and purity by mercury catalyzed cyclization. Addition of low concentrations of MEC (1-2\%) to commercial lithium ion battery electrolytes (LiPF6 in carbonates) improves the capacity retention of lithium ion batteries cycled at elevated temperature $\left(60^{\circ} \mathrm{C}\right)$. Ex situ surface analysis (XPS and FTIR) of the electrodes suggests that generation of poly (methylene-ethylene carbonate) on the anode surface results in a anode SEI with superior thermal stability 
and alters the surface chemistry of the cathode. MEC is a promising thermal stabilizing additive for lithium ion batteries.

\section{Acknowledgements}

The authors gratefully acknowledge partial financial support from the Ohio Third Frontier program OTFAEP 10-057 and the DOE EPSCoR State/National Laboratory Partnership grant in the development of the MEC SEI additive. 


\section{References}

1. K. Xu, Chem. Rev. 104 (2004) 4304.

2. C. Campion, W. Li, W.B. Euler, B.L. Lucht, B. Ravdel, J. Dicarlo, R. Gitzendanner, K.M. Abraham, Electrochem. Solid State Lett. 7 (2004) A194.

3. M. Broussely, S. Herreyre, P. Biensan, P. Kasztejna, K. Nechev, R.J. Staniewicz, J. Power Sources 97-98 (2001) 13.

4. M. Herstedt, D.P. Abraham, J.B. Kerr, K. Edstrom, Electrochem. Acta 49 (2004) 5097.

5. M. Broussely, Ph. Biensan, F. Bonhomme, Ph. Blanchard, S. Herreyre, K. Nechev, R.J. Staniewicz, J. Power Sources 146 (2005) 90.

6. L.E. Ouatani, R. Dedryvere, C. Siret, P. Biensan, S. Reynaud, P. Iratcabal, D. Gonbeau, J. Electrochem. Soc. 156 (2009) A103.

7. D. Aurbach, K. Gamolsky, B. Markovsky, Y. Gofer, M. Schmidt, U. Heider, Elec-trochim. Acta 47 (2002) 1423.

8. M.C. Smart, B.L. Lucht, B.V. Ratnakumar, J. Electrochem. Soc. 155 (2008) A557.

9. W. Li, A. Xiao, B.L. Lucht, M.C. Smart, B.V. Ratnakumar, J. Electrochem. Soc. 155 (2008) A648.

10. W. Xu, P. Bolomey, M.W. Payne, Patent Appl. US 2009/0017386.

11. M. Kotato, S. Kinoshita, Patent Appl. US 2009/0253045.

12. H. Yamamoto, H. Yamamoto, M. Nishiyama, H. Imagawa, M. Nishizawa, Tetrahedron. Lett. 47 (2006) 8369. 


\begin{tabular}{|lcccc|}
\hline & $\mathrm{C} 1 \mathrm{~s} \%$ & $\mathrm{~F} 1 \mathrm{~s} \%$ & $\mathrm{O} 1 \mathrm{~s} \%$ & $\mathrm{P} 2 \mathrm{p} \%$ \\
Fresh & 65 & 32 & 3 & - \\
$1 \mathrm{M} \mathrm{LiPF}$-formation cycling & 47 & 33 & 19 & 1 \\
$2 \% \mathrm{MEC}^{- \text {formation cycling }}$ & 53 & 21 & 26 & - \\
$1 \mathrm{MLiPF}_{6}\left(60^{\circ} \mathrm{C}\right)$ & 48 & 33 & 17 & 2 \\
$2 \% \mathrm{MEC}^{\circ}\left(60^{\circ} \mathrm{C}\right)$ & 51 & 22 & 26 & 2 \\
\hline
\end{tabular}

Table 3-1. Elemental composition of $\mathrm{C}, \mathrm{F}, \mathrm{O}$ and $\mathrm{P}$ on anodes 


\begin{tabular}{|lccccc|}
\hline & $\mathrm{C} 1 \mathrm{~s} \%$ & $\mathrm{~F} 1 \mathrm{~s} \%$ & $\mathrm{O} 1 \mathrm{~s} \%$ & $\mathrm{P} 2 \mathrm{p} \%$ & $\mathrm{Ni} 2 \mathrm{p} \%$ \\
Fresh & 43 & 31 & 11 & - & 15 \\
$1 \mathrm{M} \mathrm{LiPF}_{6}$-formation cycling & 47 & 29 & 10 & - & 14 \\
$2 \% \mathrm{MEC}$-formation cycling & 52 & 23 & 16 & - & 9 \\
$1 \mathrm{MLiPF}_{6}\left(60^{\circ} \mathrm{C}\right)$ & 43 & 31 & 10 & 1 & 15 \\
$2 \% \mathrm{MEC}\left(60^{\circ} \mathrm{C}\right)$ & 55 & 15 & 21 & 1 & 8 \\
\hline
\end{tabular}

Table 3-2. Elemental composition of C, F, O, P and Ni on cathodes 


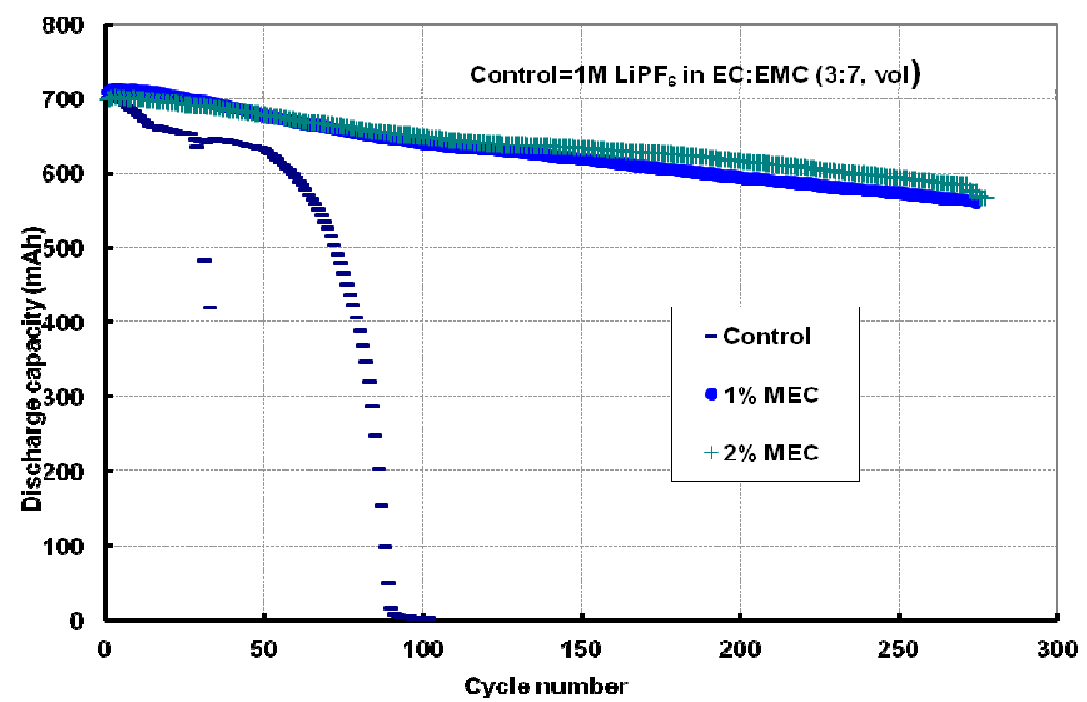

Figure 3-1. Discharge capacity vs cycle number for $\mathrm{Li}\left[\mathrm{Ni}_{1 / 3} \mathrm{Co}_{1 / 3} \mathrm{Mn}_{1 / 3}\right] \mathrm{O}_{2}$-based cells containing $1 \mathrm{M} \mathrm{LiPF}_{6}$ in 3:7 EC/EMC with and without added MEC. The cells were cycled at $1 \mathrm{C}$ rate between 3.0 and $4.2 \mathrm{~V}$ at $60^{\circ} \mathrm{C}$. 

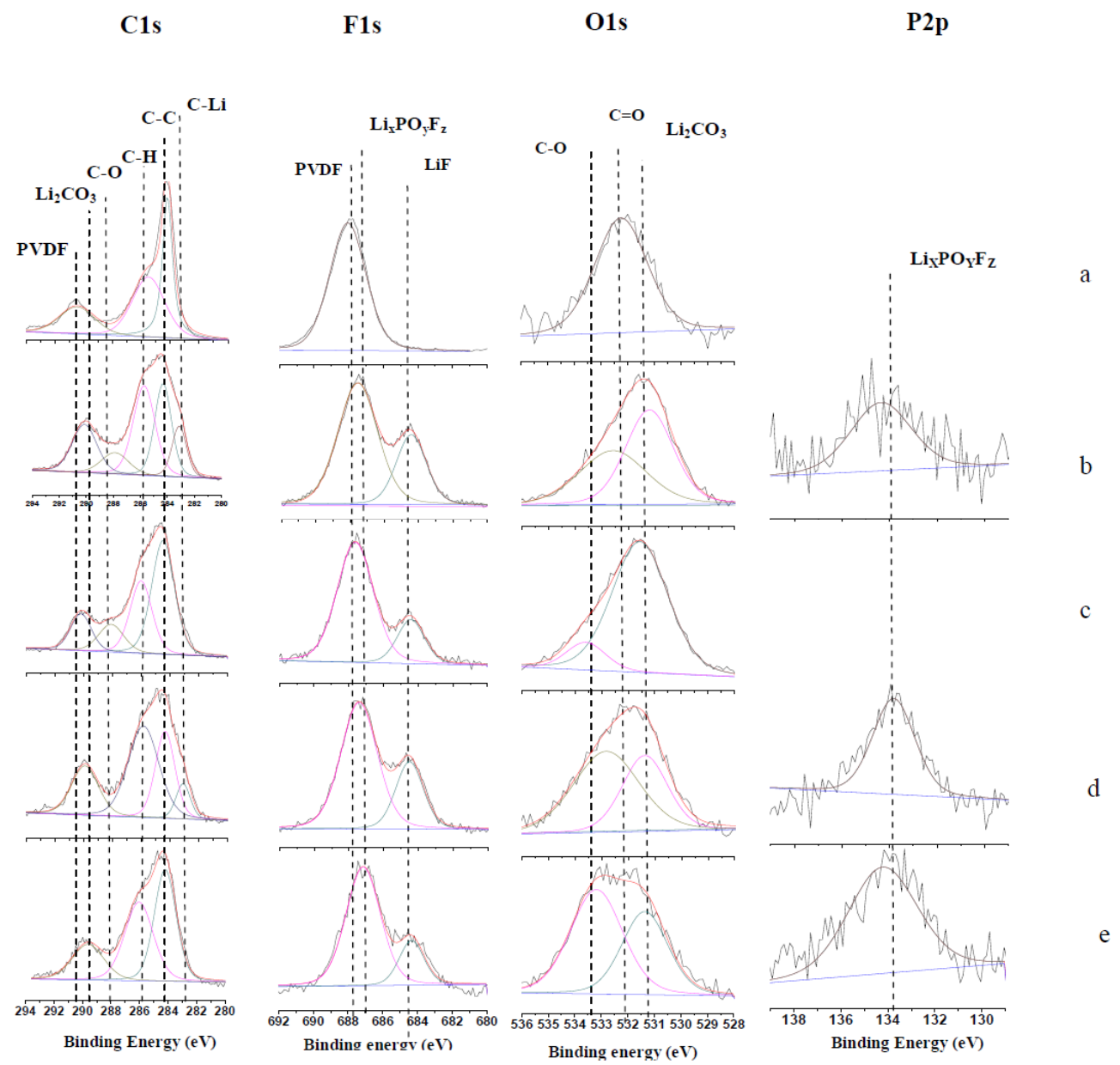

Figure 3-2. XPS spectra of anodes (a)Fresh anode (b) 1MLiPF6 in EC:EMC:DEC(1:1:1) formation cycling; (c) $1 \mathrm{MLiPF}_{6}$ in EC:EMC:DEC(1:1:1) +2\% additive formation cycling; (d) $1 \mathrm{MLiPF}_{6}$ in EC:EMC:DEC formation cycling and stored at $60^{\circ} \mathrm{C}$ for seven days and cycled at $\mathrm{C} / 5$ rate for 30cycles; (e) $1 \mathrm{MLiPF}_{6}$ in EC:EMC:DEC(1:1:1) $+2 \%$ additive formation cycling and stored at $60^{\circ} \mathrm{C}$ for seven days and cycled a $\mathrm{C} / 5$ rate for 30 cycles. 

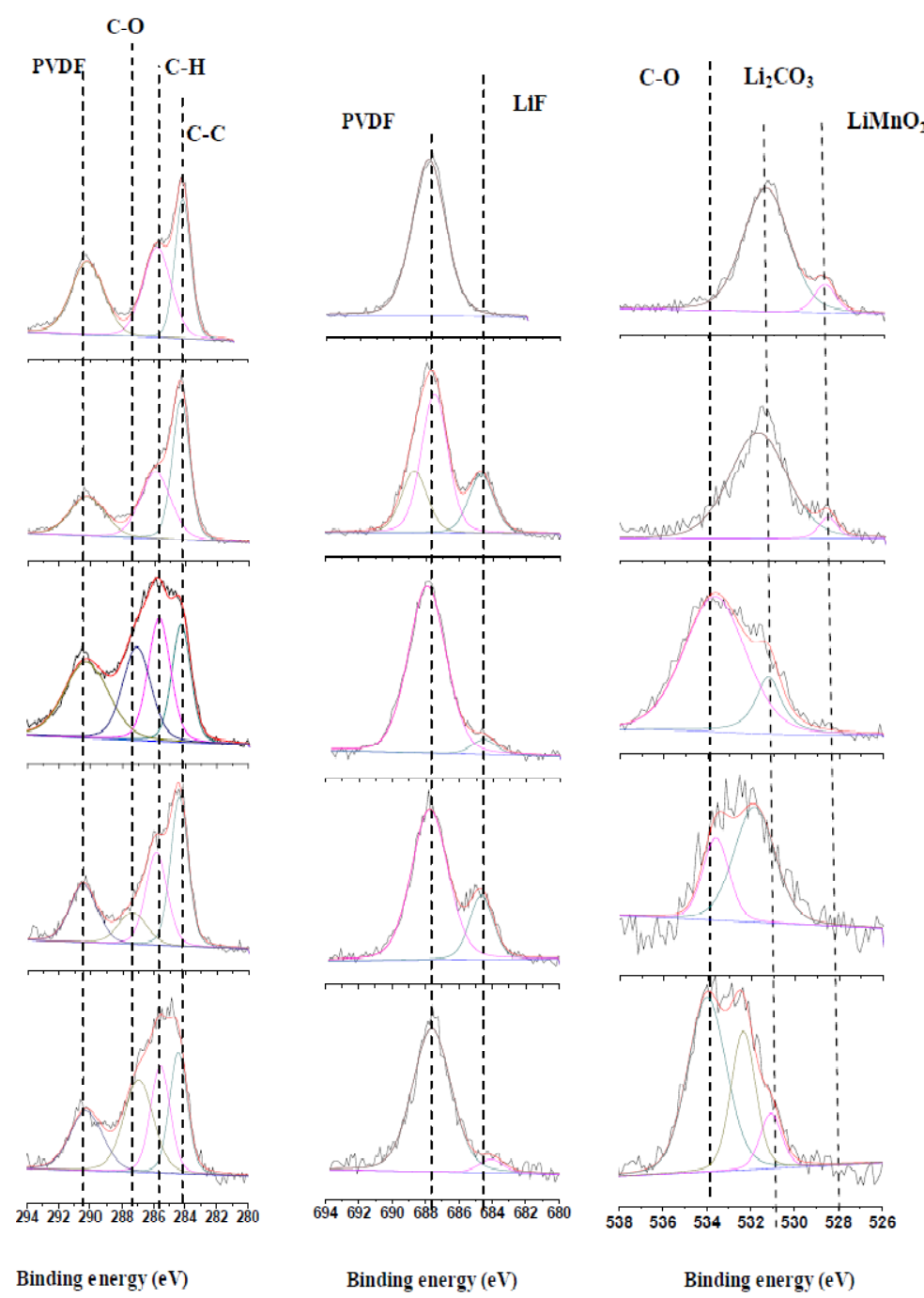

a

$\mathrm{b}$

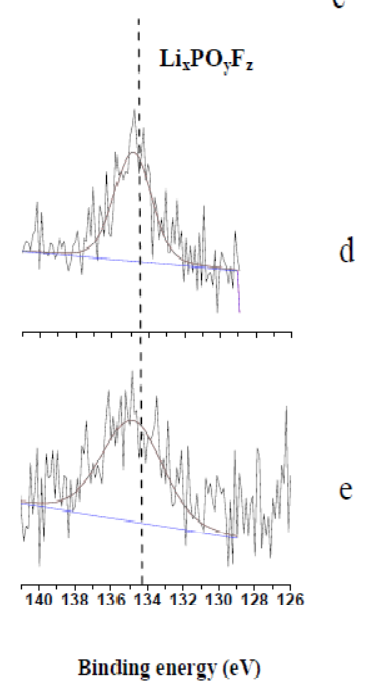

Figure 3-3. XPS spectra of cathodes (a)Fresh cathode (b) 1MLiPF6 in EC:EMC:DEC(1:1:1) formation cycling; (c) $1 \mathrm{MLiPF}_{6}$ in EC:EMC:DEC(1:1:1) +2\% additive formation cycling; (d) $1 \mathrm{MLiPF}_{6}$ in EC:EMC:DEC formation cycling and stored at $60^{\circ} \mathrm{C}$ for seven days and cycled at $\mathrm{C} / 5$ rate for 30 cycles; (e) $1 \mathrm{MLiPF}_{6}$ in EC:EMC:DEC(1:1:1) $+2 \%$ additive formation cycling and stored at $60^{\circ} \mathrm{C}$ for seven days and cycled at $\mathrm{C} / 5$ rate for 30 cycles. 


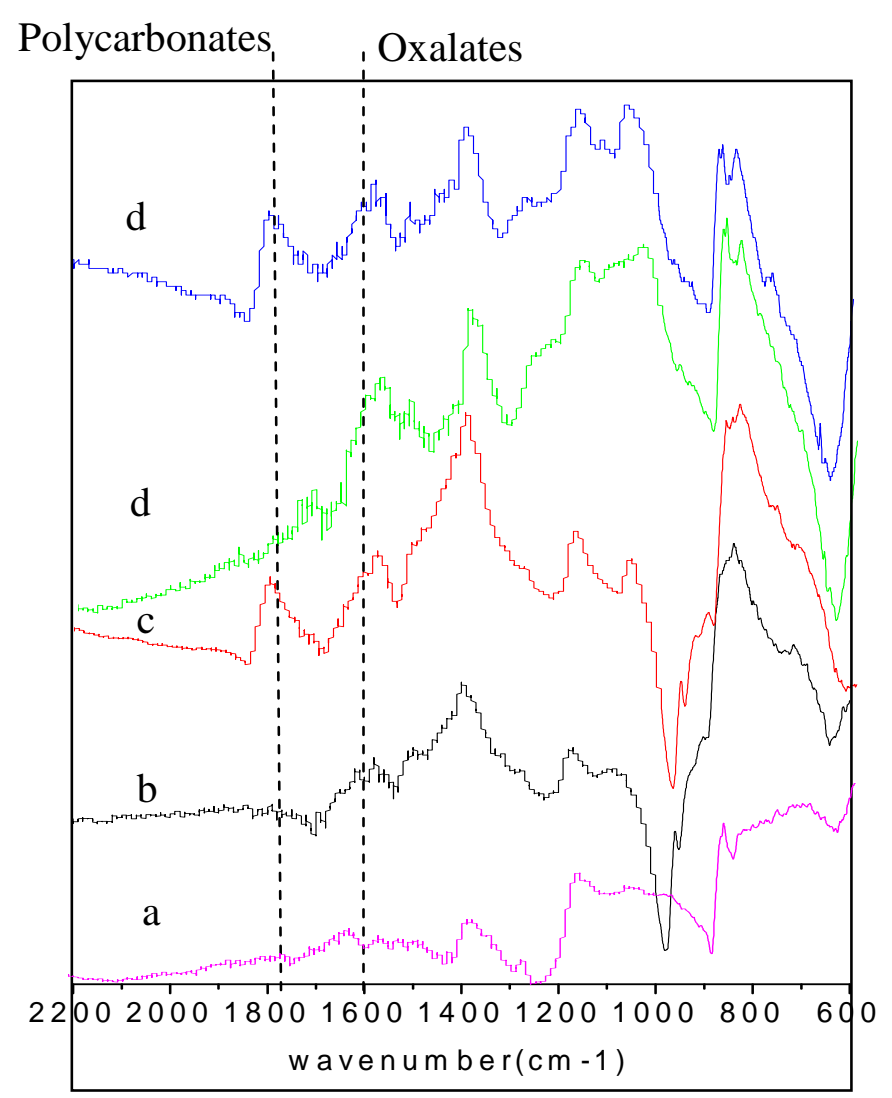

Figure 3-4. FTIR spectra of anodes (a) fresh anode(b) 1MLiPF6 in EC:EMC:DEC(1:1:1) formation cycling; (c) $1 \mathrm{MLiPF}_{6}$ in EC:EMC:DEC(1:1:1) $+2 \%$ additive formation cycling; (d) ) $1 \mathrm{MLiPF}_{6}$ in EC:EMC:DEC formation cycling and stored at $60^{\circ} \mathrm{C}$ for seven days and cycled at $\mathrm{C} / 5$ rate for 30 cycles; (e) $1 \mathrm{MLiPF}_{6}$ in EC:EMC:DEC(1:1:1) $+2 \%$ additive formation cycling and stored at $60{ }^{\circ} \mathrm{C}$ for seven days and cycled a $\mathrm{C} / 5$ rate for 30 cycles. 


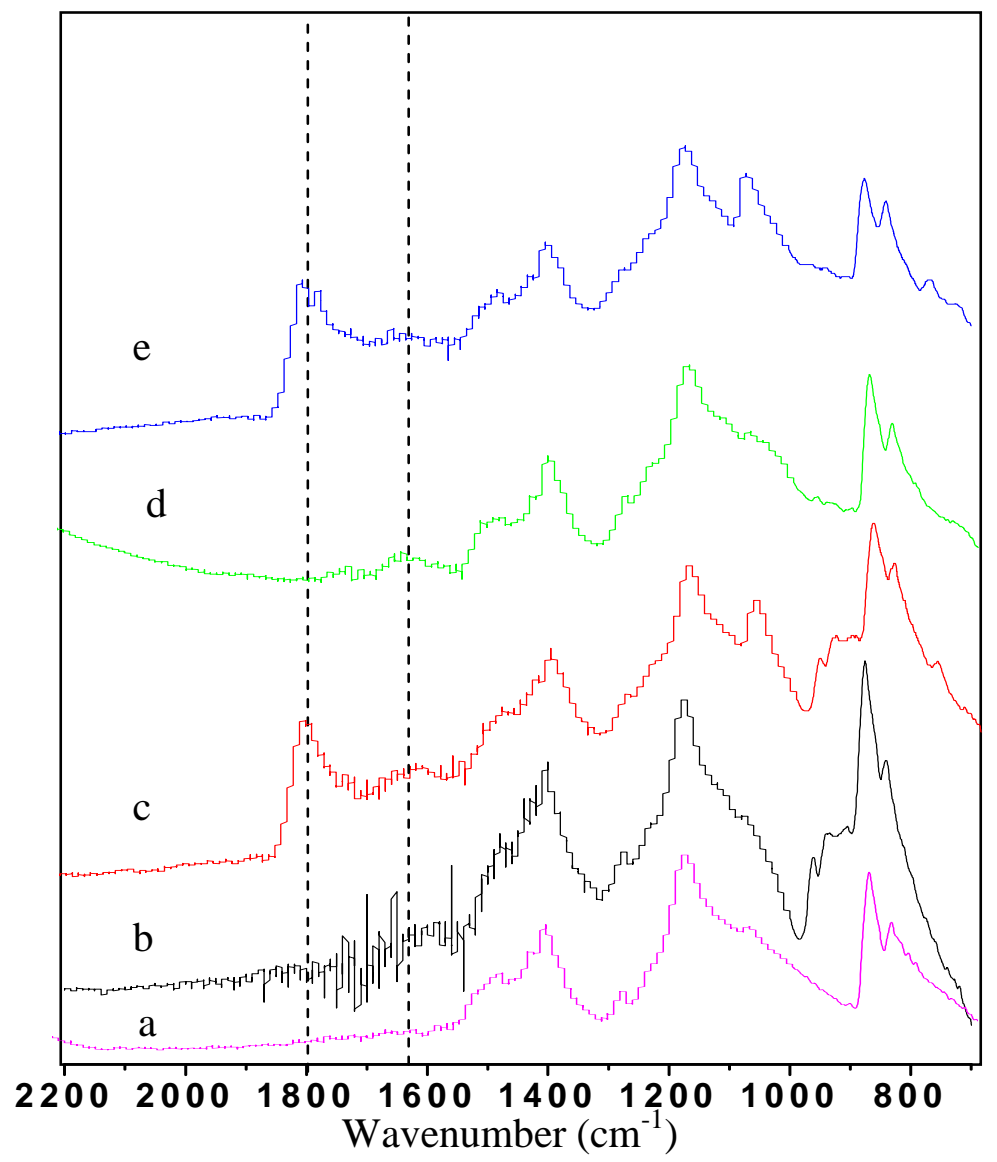

Figure 3-5. FTIR spectra of cathodes(a)fresh anode (b) 1MLiPF6 in EC:EMC:DEC(1:1:1) formation cycling; (c) $1 \mathrm{MLiPF}_{6}$ in EC:EMC:DEC(1:1:1) $+2 \%$ additive formation cycling; (d) $1 \mathrm{MLiPF}_{6}$ in EC:EMC:DEC formation cycling and stored at $60{ }^{\circ} \mathrm{C}$ for seven days and cycled at $\mathrm{C} / 5$ rate for 30 cycles; (e) $1 \mathrm{MLiPF}_{6}$ in EC:EMC:DEC(1:1:1) $+2 \%$ additive formation cycling and stored at $60{ }^{\circ} \mathrm{C}$ for seven days and cycled a $\mathrm{C} / 5$ rate for 30 cycles. 


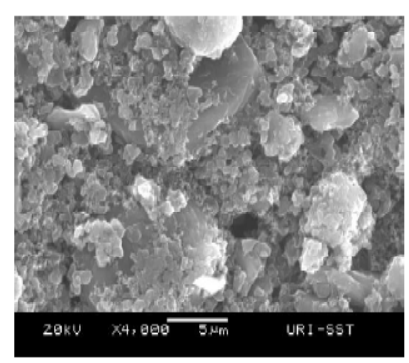

(a)

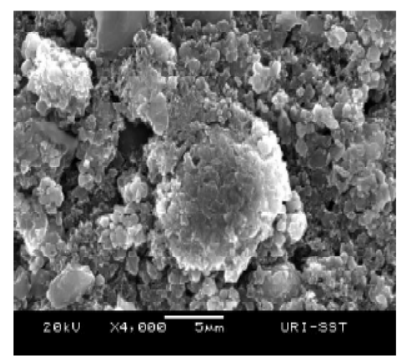

(b)

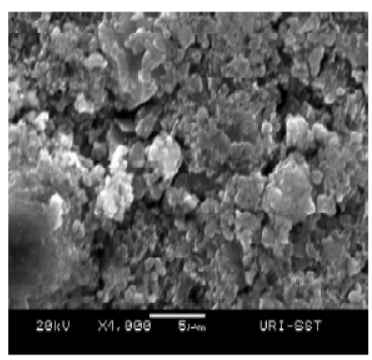

(c)

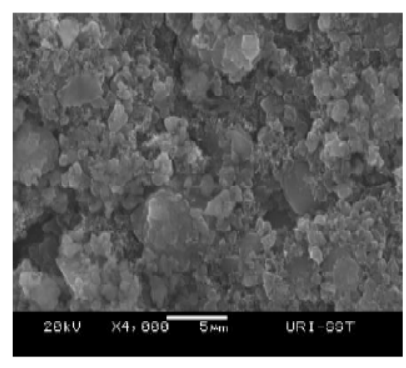

(d)

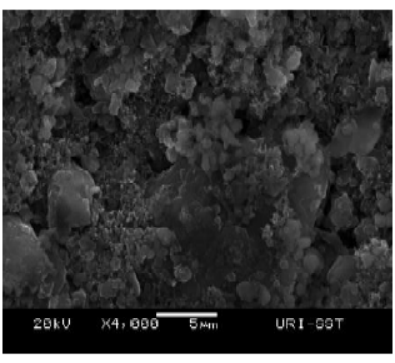

(e)

Figure 3-6. SEM images of anodes (a) fresh, (b) after formation cycling, (c) after formation cycling with MEC, (d) after cycling and storage, (e) after cycling and storage with MEC 


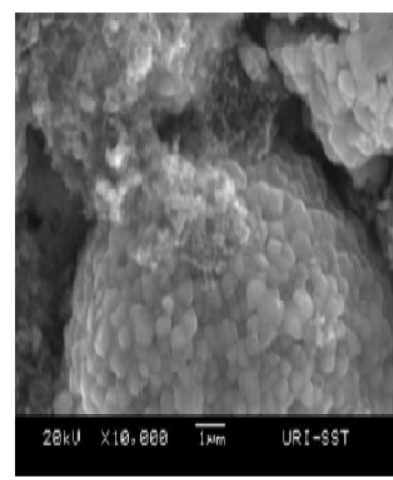

a

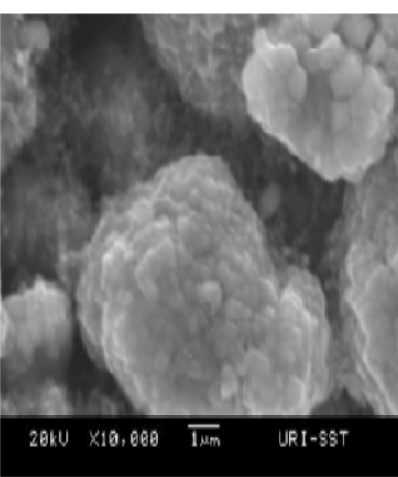

b

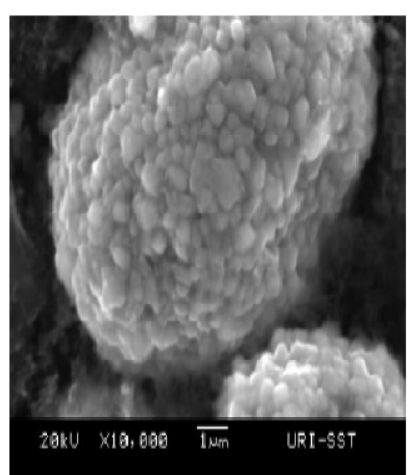

C

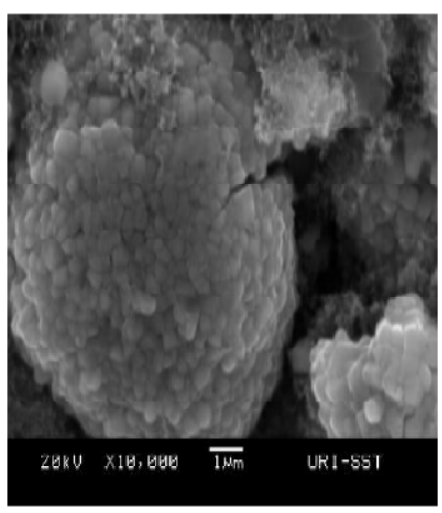

d

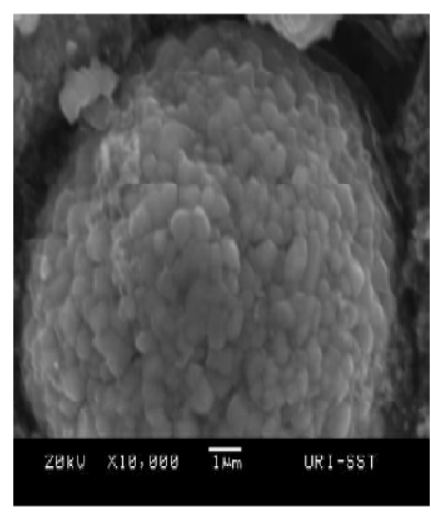

e

Figure 3-7. SEM images of cathode (a) fresh, (b) after formation cycling, (c) after formation cycling with MEC, (d) after cycling and storage, (e) after cycling and storage with MEC 


\section{MANUSCRIPIT - III}

Published in ECS Electrochemistry letters July 2012

\section{Reactivity of Electrolytes for Lithium-Oxygen batteries with $\mathrm{Li}_{2} \mathrm{O}_{2}$}

Dinesh Chalasani and Brett L. Lucht.

Department of Chemistry, University of Rhode Island Kingston, RI, USA

Corresponding Author: Dr. Brett L. Lucht.

Department of Chemistry

University of Rhode Island

Pastore Hall, 51 Lower college Rd.

Kingston, RI, 02881, USA.

Phone +1-401-874-5071.

Email address: blucht@chm.uri.edu 


\section{Chapter-4 Reactivity of electrolytes for Lithium-Oxygen Batteries with $\mathrm{Li}_{2} \mathrm{O}_{2}$ Introduction}

The development of a rechargeable $\mathrm{Li}-\mathrm{O}_{2}$ battery could result in an electrochemical energy storage device with significantly greater energy density than the conventional Li-ion batteries. ${ }^{1-4}$ Thus, there has been significant recent interest in the development of $\mathrm{Li}-\mathrm{O}_{2}$ batteries. ${ }^{3-9}$ Most currently investigated $\mathrm{Li}-\mathrm{O}_{2}$ batteries are composed of a lithium metal anode, a organic electrolyte, and a porous carbon cathode. The electrochemical reaction occurring within the cells during discharge has been reported to be $\mathrm{O}_{2}+2 \mathrm{Li} \rightarrow \mathrm{Li}_{2} \mathrm{O}_{2}$, while the reverse reaction occurs during charging. Unfortunately, there are several problems associated with rechargeablity of the current $\mathrm{Li}-\mathrm{O}_{2}$ battery system. One of the primary problems is the stability of the electrolyte in the presence of the electrode materials or reactive intermediate species generated during the reversible charging and discharging of the cell. ${ }^{10-13}$

Initial investigations used electrolytes similar to those used in lithium ion batteries, $\mathrm{LiPF}_{6}$ in carbonates. ${ }^{1,2,9}$ However, carbonate solvents have been reported to be unstable to oxidation in $\mathrm{Li}-\mathrm{O}_{2}$ cells. ${ }^{10-12}$ Other studies have investigated the use of glymes as solvents for $\mathrm{Li}-\mathrm{O}_{2}$ batteries but problems with the solvents have still been encountered..$^{3,11}$ In addition, the stability of the lithium salts used in the electrolyte has also been questioned. One reactive species which is generated during cycling, lithium superoxide $\left(\mathrm{LiO}_{2}\right)$, has recently been reported to react with lithium bis(oxalato borate) $(\mathrm{LiBOB}) .^{13}$

In order to develop a superior electrolyte system for $\mathrm{Li}-\mathrm{O}_{2}$ batteries, a better understanding of the reactivity of the electrolytes with cell components and reactive 
intermediate species must be developed. $\mathrm{Li}_{2} \mathrm{O}_{2}$ is the species generated within the pores of the carbon cathode during discharge. Thus, the electrolyte must be stable in the presence of $\mathrm{Li}_{2} \mathrm{O}_{2}$ to afford long term cyclability of $\mathrm{Li}^{-} \mathrm{O}_{2}$ batteries. We have conducted a detailed analysis of the reaction of common electrolytes with $\mathrm{Li}_{2} \mathrm{O}_{2}$ at moderate temperatures $\left(55^{\circ} \mathrm{C}\right)$ to simulate accelerated aging. Electrolytes investigated include solutions of salts $\left(\mathrm{LiPF}_{6}, \mathrm{LiBF}_{4}, \mathrm{LiBOB}\right.$, and lithium Bis(trifluoromethanesulfony)limide (LiTFSI)) in different solvents (carbonates, glymes, and nitriles). Significant differences in the reactivity of different salts was observed suggesting that $\mathrm{LiPF}_{6}$ should not be used in $\mathrm{Li}_{-} \mathrm{O}_{2}$ battery electrolytes.

\section{Experimental}

Battery grade $\mathrm{LiPF}_{6}, \mathrm{LiBF}_{4}$, Lithium bisoxalatoborate (LiBOB), and lithium trifluorosulfonylimide (LiTFSI) were obtained from Novolyte or Aldrich. Propylene carbonate (PC), Ethylene carbonate (EC), Ethyl methyl carbonate (EMC), Diethyl carbonate(DEC), Dimethoxyethane (DME), tetraethylene glycol dimethyl ether (TGDME), and Acetonitrile (ACN) were obtained from Novolyte or Acros. All the solvents were dried over $4 \mathrm{~A}^{\circ}$ molecular sieves for one week prior to use. $\mathrm{Li}_{2} \mathrm{O}_{2}(99.9$ $\%$ ) was purchased from Alfa-aeser and used without any further purification. $\mathrm{Li}_{2} \mathrm{O}$ (97\%) was obtained from Aldrich. NMR tubes were prepared with 1M salt in ternary solvent (EC: EMC: DEC), PC, TGDME or ACN. Various concentrations of $\mathrm{Li}_{2} \mathrm{O}_{2}(1$, 0.5 and $0.25 \mathrm{eq}$ ) were added to the above prepared electrolyte systems. All NMR tubes were prepared in an argon filled glove box and flame sealed under nitrogen. NMR tubes were then stored at $55^{\circ} \mathrm{C}$. NMR spectra were acquired with a Bruker $300-\mathrm{MHz}$ NMR spectrometer. The NMR data was processed by mestrenova software. The solid 
residue present after thermal storage of $\mathrm{Li}_{2} \mathrm{O}_{2}$ in $\mathrm{LiPF}_{6}$ in $\mathrm{ACN}$ or TGDME and LiTFSI in ACN or diglyme was analyzed by X-ray photoelectron spectroscopy (XPS) and Raman spectroscopy. XPS spectra were acquired on PHI5500 system using Al K $\alpha$ radiation $(\mathrm{h} v=1486.6 \mathrm{eV})$ under ultra high vaccum. The $\mathrm{C}-\mathrm{H}$ peak $(285 \mathrm{eV})$ is used as a reference peak for final adjustment of energy spectra. The spectra obtained were analyzed by Multipak (6.1A) software and fitted with XPS peak software (version 4.1). The Raman spectroscopy is performed on a Bruker optics FT-Raman microscope using a $785 \mathrm{~nm}$ excitation wavelength and 50x microscope objective. The Raman shifts were collected in a range of $3500-150 \mathrm{~cm}^{-1}$.

\section{Results and Discussion}

The reactivity of a $\mathrm{LiPF}_{6}$ in a 1:1:1 mixture of ethylene carbonate (EC)/dimethyl carbonate (DMC)/diethyl carbonate (DEC) electrolyte with $\mathrm{Li}_{2} \mathrm{O}_{2}$ was investigated by ${ }^{1} \mathrm{H},{ }^{19} \mathrm{~F}$ and ${ }^{31} \mathrm{P}$ NMR spectroscopy. NMR spectra of fresh samples of electrolyte contain a single ${ }^{19} \mathrm{~F}$ resonance centered at $65 \mathrm{ppm}$ (doublet, $709 \mathrm{~Hz}$ ) and a single ${ }^{31} \mathrm{P}$ resonance at $-145 \mathrm{ppm}$ (septet, $709 \mathrm{~Hz}$ ) characteristic of a single $\mathrm{P}$ atom bound to six $\mathrm{F}$ atoms as expected for $\mathrm{LiPF}_{6} \cdot{ }^{14}$ The ${ }^{1} \mathrm{H}$ NMR spectrum contains two singlets at 4.51 and $3.72 \mathrm{ppm}$, characteristic of EC and DMC, respectively, and a broad quartet and triplet at 1.24 and $4.14 \mathrm{ppm}$ characteristic of DEC, respectively. Upon addition of 0.5 molar equivalents of $\mathrm{Li}_{2} \mathrm{O}_{2}$ to $1 \mathrm{M}$ solutions of $\mathrm{LiPF}_{6}$ in 1:1:1 EC/EMC/DEC gas evolution was initiated. The samples were stored at $55{ }^{\circ} \mathrm{C}$ for $20 \mathrm{hrs}$. Two new sets of resonances are observed in the ${ }^{19} \mathrm{~F}$ NMR spectrum. The singlet at $-17 \mathrm{ppm}$ in the ${ }^{19} \mathrm{~F}$ spectrum is attributed to $\mathrm{LiF}$. The second set of resonances in the ${ }^{19} \mathrm{~F}$ NMR spectrum 
is a doublet at $54 \mathrm{ppm}(940 \mathrm{~Hz})$. The appearance of the new doublet in the ${ }^{19} \mathrm{~F}$ NMR spectrum coincides with the appearance of a new triplet in the ${ }^{31} \mathrm{P}$ NMR spectrum at $20 \mathrm{ppm}(940 \mathrm{~Hz}) . \quad \mathrm{A}{ }^{19} \mathrm{~F}$ doublet coupled to a ${ }^{31} \mathrm{P}$ triplet is consistent with a $\mathrm{P}$ atom bound to two $\mathrm{F}$ atoms supporting the formation of $\mathrm{OPF}_{2} \mathrm{OLi}$ (Figure 1). There were no observable changes in the ${ }^{1} \mathrm{H}$ NMR spectra (Figure 2). Continued storage of the electrolyte for two weeks results in only small changes to the spectra supporting a slow increase in the concentration of $\mathrm{LiF}$ and $\mathrm{O}=\mathrm{PF}_{2} \mathrm{OLi}$ but no changes to the carbonate solvents were observed. Extended storage in carbonate based solvents at 55 ${ }^{\circ} \mathrm{C}$ (two weeks) results in the generation of $\mathrm{OPF}(\mathrm{OLi})_{2}$ evidenced by a doublet in ${ }^{19} \mathrm{~F}$ spectra $\sim 60 \mathrm{ppm}(920 \mathrm{~Hz})$ and a doublet in ${ }^{31} \mathrm{P}$ spectra $-10 \mathrm{ppm}(920 \mathrm{~Hz})$ consistent with further thermal decomposition of the $\mathrm{LiPF}_{6} /$ carbonate electrolyte as previously reported. ${ }^{15}$ Additional storage experiments were conducted with different ratios of $\mathrm{Li}_{2} \mathrm{O}_{2}$ to $\mathrm{LiPF}_{6}$ in 1:1:1 EC/EMC/DEC and provide the same decomposition products. The concentration of $\mathrm{OPF}_{2}(\mathrm{OLi})$ determined by integration of the ${ }^{19} \mathrm{~F}$ NMR signals is consistent with quantitative decomposition of the $\mathrm{Li}_{2} \mathrm{O}_{2}$. Similar reactions conducted at room temperature support the generation of the same products at a slower rate. Storage for $20 \mathrm{hrs}$ at room temperature results in the generation of approximately 50 $\%$ of the $\mathrm{OPF}_{2}(\mathrm{OLi})$ generated upon storage for $20 \mathrm{hrs}$ at $55^{\circ} \mathrm{C}$.

Similar investigations were conducted on $\mathrm{LiPF}_{6}$ in other solvent systems. The spectral features of $\mathrm{LiPF}_{6}$ are largely independent of the solvent (EC/DEC/DMC, PC, tetraglyme, and $\mathrm{ACN}$ ). Storage of $1 \mathrm{M}$ solutions of $\mathrm{LiPF}_{6}$ in $\mathrm{PC}$ resulted in very similar spectral changes as observed in EC/DMC/DEC. New ${ }^{19} \mathrm{~F}$ and ${ }^{31} \mathrm{P}$ NMR resonances were observed characteristic of $\mathrm{LiF}$ and $\mathrm{OPF}_{2} \mathrm{OLi}$ and no changes were 
observed to the ${ }^{1} \mathrm{H}$ NMR signals for PC. Storage of of $1 \mathrm{M} \mathrm{LiPF}_{6}$ solutions of tertraglyme provided slightly different results. The reaction of $\mathrm{Li}_{2} \mathrm{O}_{2}$ with $\mathrm{LiPF}_{6}$ was very slow at $55{ }^{\circ} \mathrm{C}$. However, upon increasing the temperature of the mixture to $90{ }^{\circ} \mathrm{C}$ for 24 hours a rapid reaction between $\mathrm{LiPF}_{6}$ and $\mathrm{Li}_{2} \mathrm{O}_{2}$ occurs. The changes to the ${ }^{19} \mathrm{~F}$ and ${ }^{31} \mathrm{P}$ NMR spectra were very similar to that observed for the carbonates consistent with the formation of $\mathrm{LiF}$ and $\mathrm{OPF}_{2} \mathrm{OLi}$. The small difference in reactivity for tetraglyme compared to carbonates is likely due to the lower solubility of $\mathrm{Li}_{2} \mathrm{O}_{2}$ in tetraglyme inhibiting reaction initiation. Since both carbonates and glymes contain oxygen, related investigations of the reactivity of $\mathrm{LiPF}_{6}$ with $\mathrm{Li}_{2} \mathrm{O}_{2}$ were conducted in acetonitrile, a polar aprotic solvent containing no oxygen. The spectral changes were very similar to those observed in carbonates and glymes. New peaks were observed in the ${ }^{19} \mathrm{~F}$ and ${ }^{31} \mathrm{P}$ NMR spectra characteristic of $\mathrm{LiF}$ and $\mathrm{O}=\mathrm{PF}_{2} \mathrm{OLi}$ and no changes were observed in the ${ }^{1} \mathrm{H}$ spectra of the solvent (Figure 3). The reaction products observed in ACN confirm that $\mathrm{Li}_{2} \mathrm{O}_{2}$ is the source of oxygen. The thermal stability of $\mathrm{LiPF}_{6}$ electrolytes in the presence of $\mathrm{Li}_{2} \mathrm{O}_{2}$, the discharged cathode material for lithiumoxygen batteries, is considerably worse than in the presence of discharged metal oxide used in lithium ion batteries. ${ }^{16}$

The reaction of other salts including $\mathrm{LiBOB}, \mathrm{LiBF}_{4}$ and LiTFSI with $\mathrm{Li}_{2} \mathrm{O}_{2}$ were investigated in the presence of PC and DME. The reactions were monitored by ${ }^{11} \mathrm{~B}$, ${ }^{19} \mathrm{~F}$ and ${ }^{1} \mathrm{H}$ NMR spectroscopy of the salts and solvents. The spectral features, after storage at $55{ }^{\circ} \mathrm{C}$ for two weeks, were identical to the pure individual components indicating no deterioration of the electrolyte. Subsequent ${ }^{19} \mathrm{~F}$ and ${ }^{1} \mathrm{H}$ NMR 
experiments suggest that there is no degradation of LiTFSI in DME upon storage for an additional two weeks at $85^{\circ} \mathrm{C}$ (Figure 4).

\section{Surface analysis}

The surfaces of the residual solid after storage of $\mathrm{Li}_{2} \mathrm{O}_{2}$ at elevated temperature were analyzed via a combination of XPS and Raman spectroscopy. Analysis of commercial $\mathrm{Li}_{2} \mathrm{O}_{2}$ reveals a strong peak in the $\mathrm{O} 1 \mathrm{~s}$ spectrum at $531 \mathrm{eV}$ characteristic of $\mathrm{Li}_{2} \mathrm{O}_{2}$. Trace quantities of lithium carbonate as a surface impurity were also evidenced by $\mathrm{C}$ 1s $(290 \mathrm{eV})$ and $\mathrm{O}$ 1s spectra $(532.7 \mathrm{eV})$ along with the universal carbon contamination peak at $285 \mathrm{eV}$ in the $\mathrm{C} 1 \mathrm{~s}$ spectrum (Figure 5). The surface of the solid residue recovered from the reaction of 0.5 eq $\mathrm{Li}_{2} \mathrm{O}_{2} / 1$ eq $\mathrm{LiPF}_{6} / \mathrm{ACN}$ has very low concentrations of $\mathrm{C}(4.2 \%)$ and $\mathrm{O}(8.6 \%)$ and a very high concentration of $\mathrm{F}$ (87.2\%), as determined by XPS. The C 1s XPS spectra of the solid residue recovered from the reaction of 0.5 eq $\mathrm{Li}_{2} \mathrm{O}_{2} / 1$ eq $\mathrm{LiPF}_{6} / \mathrm{ACN}$ contains only the universal carbon contamination peak. The $\mathrm{O} 1 \mathrm{~s}$ spectrum has low intensity suggesting a low concentration of $\mathrm{Li}_{2} \mathrm{O}_{2}, \mathrm{Li}_{2} \mathrm{O}$, and $\mathrm{Li}_{\mathrm{x}} \mathrm{PO}_{\mathrm{y}} \mathrm{F}_{\mathrm{z}}$ on the surface of the residue. The $\mathrm{F} 1 \mathrm{~s}$ spectrum contains significant peaks consistent with $\mathrm{LiF}(685 \mathrm{eV})$ along with lower concentrations of $\mathrm{Li}_{x} \mathrm{PO}_{\mathrm{y}} \mathrm{F}_{\mathrm{z}}(687 \mathrm{eV})$ and $\mathrm{LiPF}_{6}(688 \mathrm{eV})$. The XPS spectra of solid residues of 0.5 eq $\mathrm{Li}_{2} \mathrm{O}_{2}$ in LiTFSI/DME are very similar to the XPS spectra to a mixture of $\mathrm{Li}_{2} \mathrm{O}_{2}$, LiTFSI and residual DME, suggesting that there is no decomposition of $\mathrm{Li}_{2} \mathrm{O}_{2}$ upon storage at elevated temperature (Figure 6).

Raman spectra (Figure 7) of the residual solid recovered from the reaction of $\mathrm{LiPF}_{6}$ with $\mathrm{Li}_{2} \mathrm{O}_{2}$ in acetonitrile does not contain peaks characteristic of $\mathrm{Li}_{2} \mathrm{O}_{2}$. New absorbances are observed consistent with decomposition to low concentrations of $\mathrm{Li}_{2} \mathrm{O}$ 
$\left(516 \mathrm{~cm}^{-1}\right)$ and other species. Similar analysis of the residual solid recovered from the storage of LiTFSI in DME with $\mathrm{Li}_{2} \mathrm{O}_{2}$ suggests that the $\mathrm{Li}_{2} \mathrm{O}_{2}$ is intact and has not reacted, consistent with NMR and XPS results.

\section{Reaction Mechanism}

The data presented above suggests that $\mathrm{LiPF}_{6}$ has very poor thermal stability in the presence of $\mathrm{Li}_{2} \mathrm{O}_{2}$ while other salts including LiTFSI, LiBOB, and $\mathrm{LiBF}_{4}$ have excellent stability in the presence of $\mathrm{Li}_{2} \mathrm{O}_{2}$. The proposed mechanism for reaction of $\mathrm{LiPF}_{6}$ with $\mathrm{Li}_{2} \mathrm{O}_{2}$ is presented in Scheme 1. While many solvents have been reported to be reactive in the presence of lithium super oxide $\left(\mathrm{LiO}_{2}\right)^{10-12}$ all of the solvents investigated (carbonates, glymes, and nitriles) have excellent stability in the presence of $\mathrm{Li}_{2} \mathrm{O}_{2}$.

$$
\begin{aligned}
& \mathrm{LiPF}_{6} \rightleftharpoons \mathrm{LiF}+\mathrm{PF}_{5} \\
& \mathrm{PF}_{5}+2 \mathrm{Li}_{2} \mathrm{O}_{2} \longrightarrow \mathrm{OPF}_{3}+2 \mathrm{LiF}+\mathrm{Li}_{2} \mathrm{O}+\mathrm{O}_{2} \\
& \mathrm{OPF}_{3}+\mathrm{Li}_{2} \mathrm{O} \longrightarrow \mathrm{OPF}_{2}(\mathrm{OLi})+\mathrm{LiF}
\end{aligned}
$$

Scheme 1

\section{Conclusions}

The thermal stability of several potentially interesting electrolytes for lithium air batteries in the presence of $\mathrm{Li}_{2} \mathrm{O}_{2}$ was investigated. Stability of the liquid electrolytes was probed by NMR spectroscopy. Electrolytes containing $\mathrm{LiPF}_{6}$ experienced a rapid decomposition of the salt to generate $\mathrm{OPF}_{2}(\mathrm{OLi})$ in solution and solid $\mathrm{LiF}$. 
Investigation of the residual solids via XPS and Raman spectroscopy supported the decomposition reactions observed in solution for $\mathrm{LiPF}_{6}$ electrolytes. However, all solvents investigated have excellent stability in the presence of $\mathrm{Li}_{2} \mathrm{O}_{2}$. In addition, other salts including LiTFSI, $\mathrm{LiBOB}$, and $\mathrm{LiBF}_{4}$ are also very stable in the presence of $\mathrm{Li}_{2} \mathrm{O}_{2}$. The results suggest that $\mathrm{LiPF}_{6}$ is a poor salt for rechargeable $\mathrm{Li}-\mathrm{O}_{2}$ batteries. The addition of $\mathrm{Li}_{2} \mathrm{O}_{2}$ to $\mathrm{LiPF}_{6}$ in carbonates results in a dramatic decrease in the thermal stability of the electrolyte.

\section{Acknowledgement}

We would like to thank the DOE EPSCoR National Laboratory Partnership program for funding of the work. 


\section{References}

(1) K. M. Abraham and Z. Jiang, J. Electrochem. Soc., 143, 1 (1996).

(2) J. Read, J. Electrochem. Soc. 149, A1190 (2002).

(3) C. O. Laoire, S. Mukerjee, E. J. Plichta, M. A. Hendrickson, and K. M. Abraham, J. Electrochem. Soc., 158, A302 (2011).

(4) M. Armand and J. M. Tarascon, Nature (London), 451, 652 (2008).

(5) W. Xu, J. Xiao, D. Wang, J. Zhang, and J.-G. Zhang, J. Electrochem. Soc., 157, A219 (2010).

(6) W. Xu, J. Xiao, D. Wang, J. Zhang, and J.-G Zhang, Electrochem. Solid-State Lett. 13, A48 (2010).

(7) Y.-C Lu, Z. Xu, H. A. Gasteiger, S. Chen, K. Hamad-Schifferli, and Y. ShaoHorn, J. Am. Chem. Soc., 132, 12170 (2010).

(8) B. Kumar, J. Kumar, R. Leese, J. P. Fellner, S. J. Rodrigues, and K. M. Abraham, J. Electrochem. Soc., 157, A50 (2010).

(9) A. Debart, A. Paterson, J. Bao, and P. G. Bruce, Angew. Chem., Int. Ed., 47, $4521(2008)$.

(10) Z. Peng, S. A. Freunberger, L. J. Hardwick, Y. Chen, V. Giordani, F. Barde, P. Novak, D. Graham, J.-M. Tarascon, and P. G. Bruce, Angew. Chem. Int. Ed. , 50, 6351 (2011).

(11) S. A. Freunberger, Y. Chen, N. E. Drewett, L. J. Hardwick, F. Barde, and P. G. Bruce, Angew. Chem. Int. Ed., 50, 8609 (2011).

(12) S. A. Freunberger, Y. Chen, Z. Peng, J. M. Griffin, L. J. Hardwick, F. Barde, P. Novak, and P. G. Bruce, J. Am. Chem. Soc. , 133, 8040 (2011). 
(13) S. H. Oh, T. Yim, E. Pomerantseva, and L. F. Nazar Electrochem. Solid State Lett. 14, A185, (2011).

(14) C. L. Campion, W. Li, W. B. Euler, B. L. Lucht, B. Ravdel, J. Dicarlo, R. Gitzendanner, and K. M. Abraham, Electrochem. \& Solid-State Lett. 7, A194 (2004).

(15) C. L. Campion, W. Li, and B. L. Lucht, J. Electrochem. Soc., 152, A2327 (2005).

(16) W. Li and B. L. Lucht J. Electrochem. Soc. 153, A1617-A1625 (2006). 


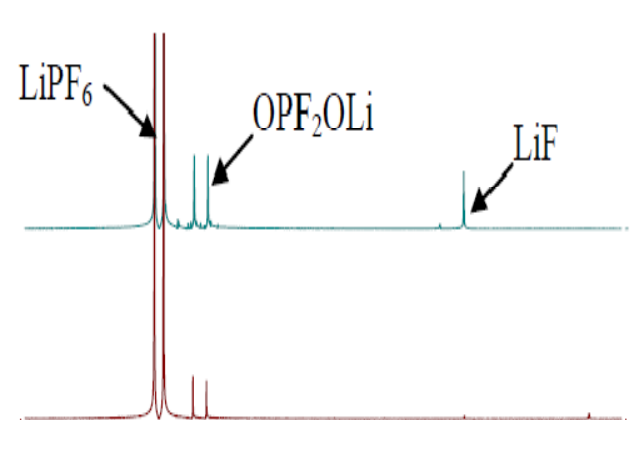

$\begin{array}{lllllllllllllllll}100 & 90 & 80 & 70 & 60 & 50 & 40 & 30 & 20 & 10 & 0 & -10 & -20 & -30 & -40 & -50\end{array}$

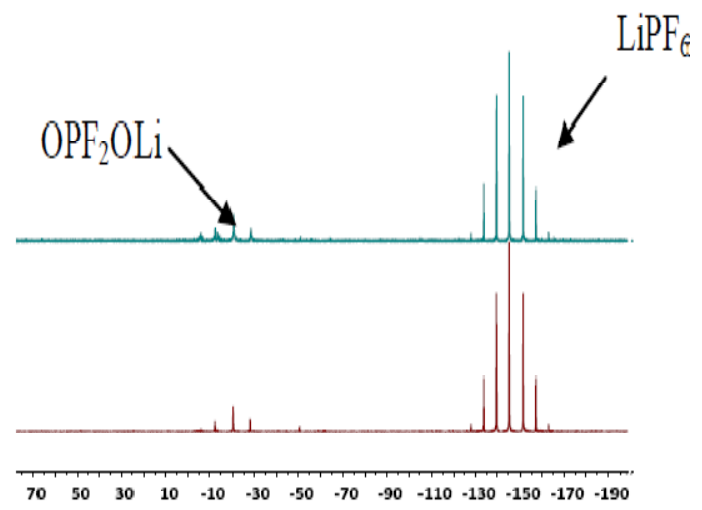

Figure 4- 1. ${ }^{19} \mathrm{~F}$ NMR (left) and ${ }^{31} \mathrm{P}$ (right) of 0.5 eq $\mathrm{Li}_{2} \mathrm{O}_{2}$ with $1 \mathrm{M} \mathrm{LiPF}_{6}$ in EC:DMC:DEC stored at $55^{\circ} \mathrm{C}$ for 2 weeks (top) and 20 hours (bottom). 


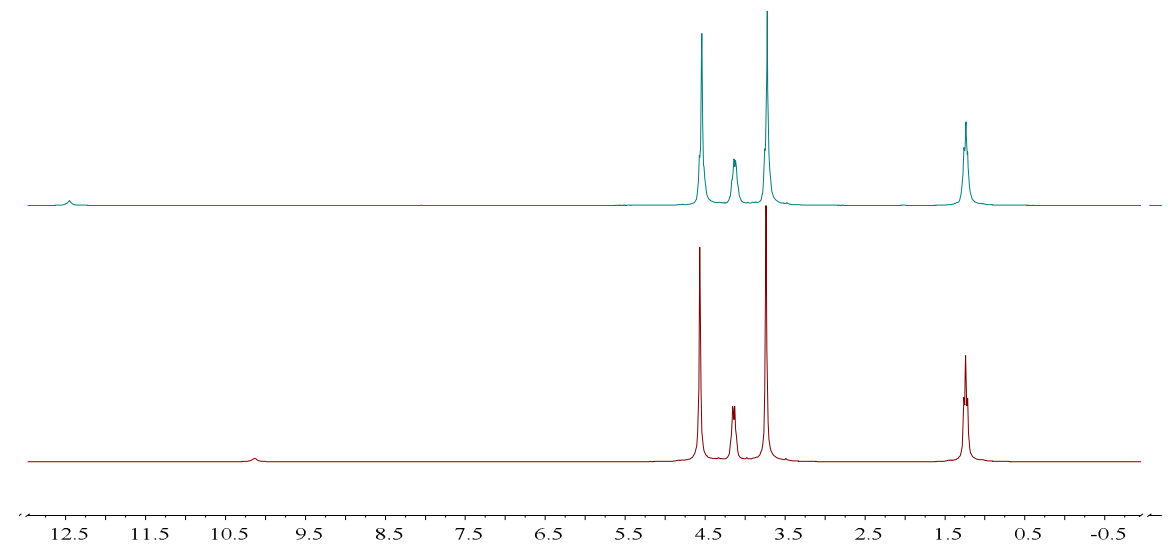

Figure 4-2. ${ }^{1} \mathrm{H} N M R$ of 0.5 eq $\mathrm{Li}_{2} \mathrm{O}_{2}$ with $1 \mathrm{M} \mathrm{LiPF}$ in EC:DMC:DEC stored at 55 ${ }^{\circ} \mathrm{C}$ for 2 weeks (top) and 20 hours (bottom). 


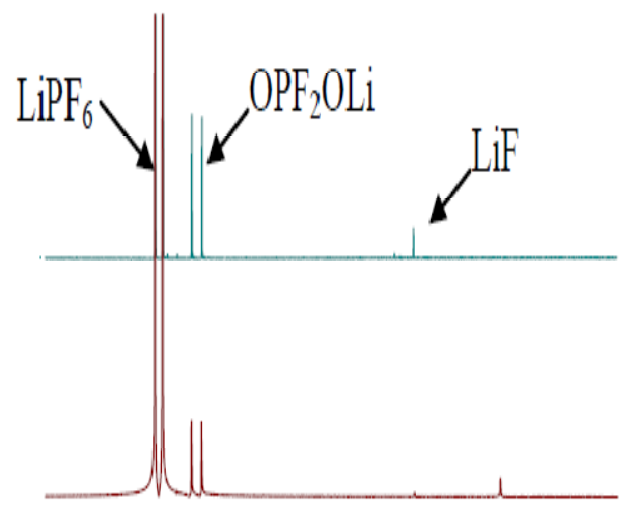

$\begin{array}{lllllllllllllllllll}100 & 90 & 80 & 70 & 60 & 50 & 40 & 30 & 20 & 10 & 0 & -10 & -20 & -30 & -40 & -50 & -60 & -70 & -8\end{array}$

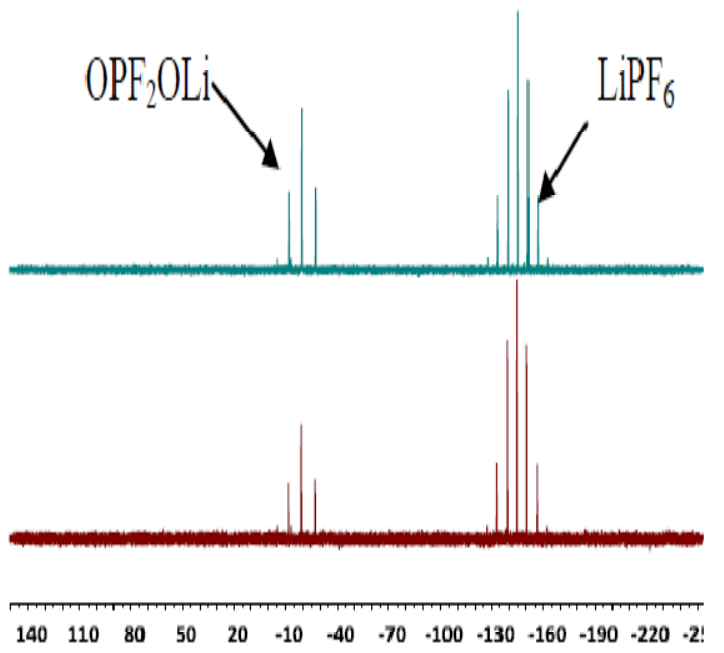

Figure 4-3. ${ }^{19} \mathrm{~F}$ NMR (left) and ${ }^{31} \mathrm{P}$ (right) of 0.5 eq $\mathrm{Li}_{2} \mathrm{O}_{2}$ with $1 \mathrm{M} \mathrm{LiPF}_{6}$ in $\mathrm{ACN}$ stored at $55{ }^{\circ} \mathrm{C}$ for 2 weeks (top) and 20 hours (bottom). 

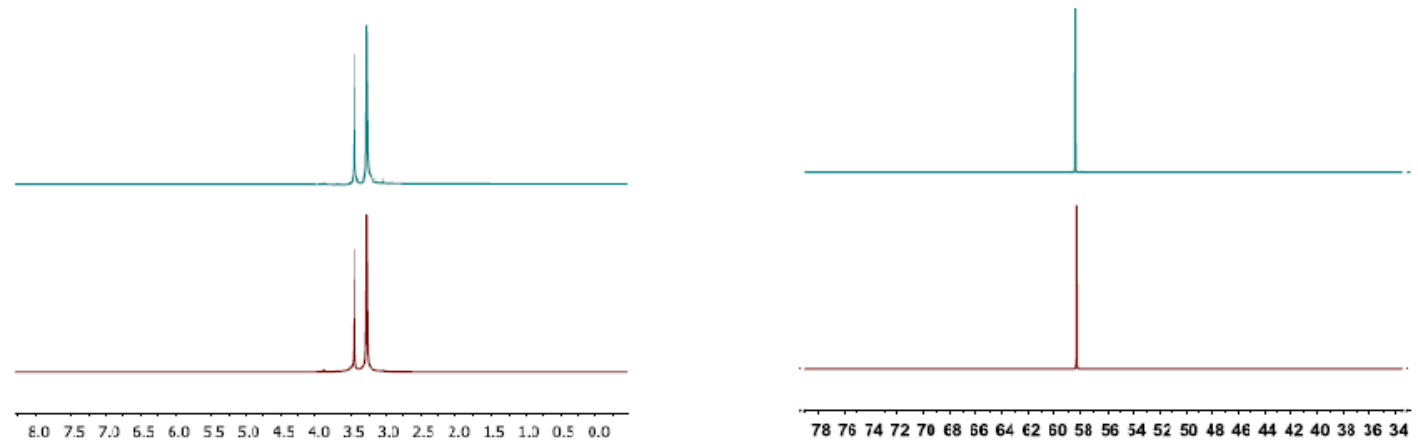

7876747270686664626058565452504846444240383634

Figure 4-4. ${ }^{1} \mathrm{H}$ (left) and ${ }^{19} \mathrm{~F}$ (right) of 0.5 eq $\mathrm{Li}_{2} \mathrm{O}_{2}$ with $1 \mathrm{M}$ LiTFSI in DME stored at $55^{\circ} \mathrm{C}$ for 2 weeks (top) and 20 hours (bottom). 

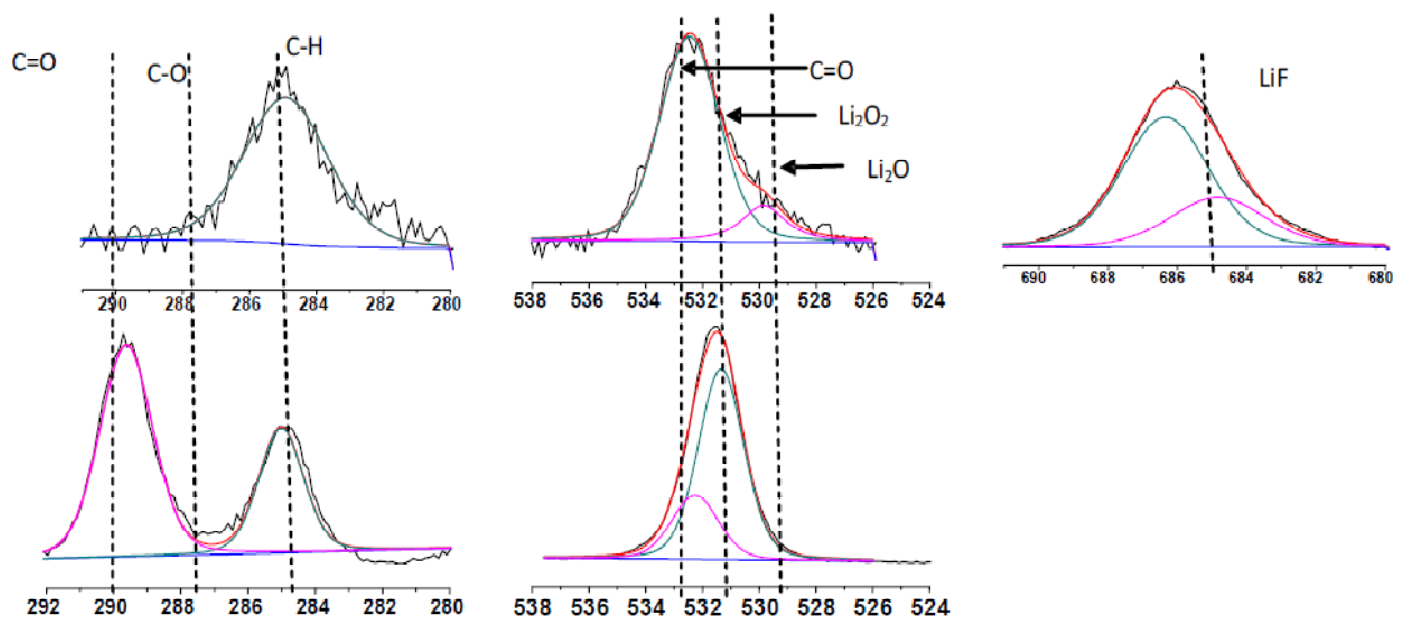

Figure 4-5. XPS spectra of the precipitate formed by reaction of 0.5 eq $\mathrm{Li}_{2} \mathrm{O}_{2}$ with $\mathrm{LiPF}_{6}$ in $\mathrm{ACN}$ (top) pure $\mathrm{Li}_{2} \mathrm{O}_{2}$ (bottom). 

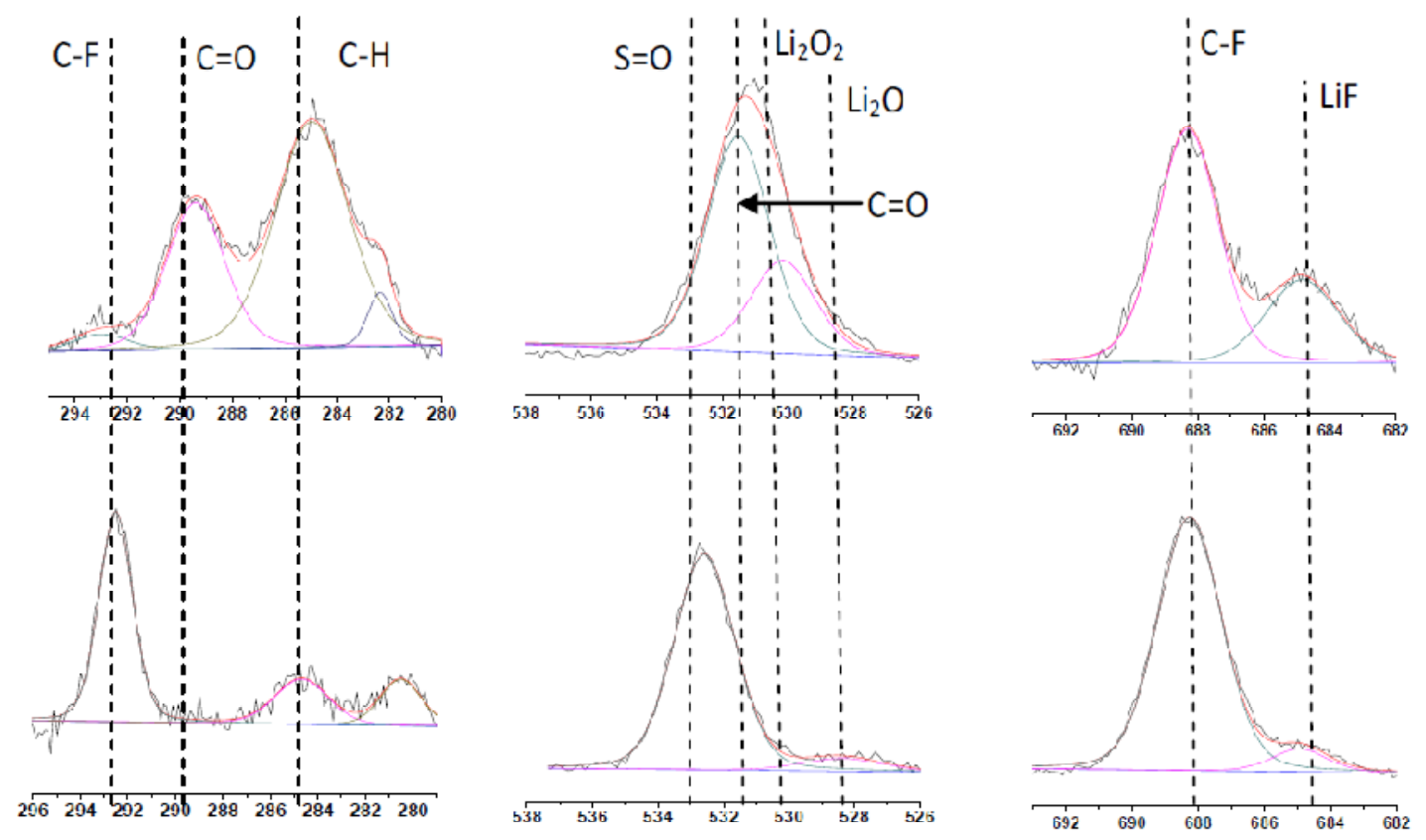

Figure 4-6. XPS spectra of the precipitate formed by reaction of 0.5 eq $\mathrm{Li}_{2} \mathrm{O}_{2}$ with LiTFSI in DME (top), and pure LiTFSI (bottom). 


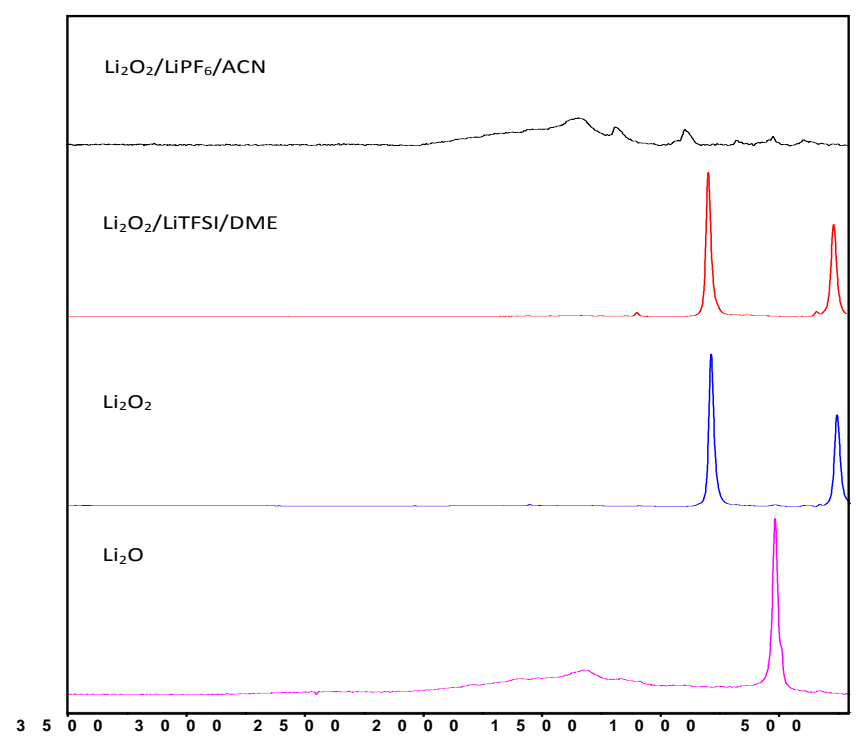

Figure 4-7. Raman spectra of solid residues from $\mathrm{Li}_{2} \mathrm{O}_{2}$ reaction with various electrolyte systems in comparison with pure $\mathrm{Li}_{2} \mathrm{O}_{2}$ and $\mathrm{Li}_{2} \mathrm{O}$. 


\begin{abstract}
MANUSCRIPIT- IV
Published in Journal of Polymer Science A, July 2010

Two-Step Thermochromism in Poly(3-docosoxy-4methylthiophene):Mechanistic Similarity to Poly(3-docosylthiophene)

Dinesh Chalasani, Joshua K. Potvin, Brett L. Lucht, William B. Euler Department of Chemistry, University of Rhode Island kingston, RI, USA
\end{abstract}

Corresponding Author: Dr. Brett L. Lucht.

Department of Chemistry

University of Rhode Island

Pastore Hall, 51 Lower college Rd.

Kingston, RI, 02881, USA.

Phone +1-401-874-5071.

Email address: blucht@chm.uri.edu 


\section{Chapter 5 Two-Step Thermochromism in Poly(3-docosoxy-4- methylthiophene):Mechanistic Similarity to Poly(3-docosylthiophene)}

\section{Introduction}

The unique electronic and spectroscopic properties of conjugated polymers have resulted in significant academic and industrial interest. ${ }^{1}$ Polythiophenes are one of the most widely investigated conjugated polymers because of the ease of synthesis and modification of solubilizing substituents. ${ }^{2}$ One of the interesting properties of substituted polythiophenes is thermochromism. Although there have been many investigations of the mechanism of the thermochromic transition, there are still questions relating to how the structure of the polythiophene (regioregularity, ${ }^{3,4}$ substitution pattern, ${ }^{5}$ molecular weight, ${ }^{6}$ impurities, ${ }^{7}$ precipitation method, ${ }^{8,9}$ etc.) affects the mechanism. ${ }^{10}$ Although most polythiophenes have a simple two-phase thermochromic transition, mesophase formation is observed in some poly (3alkylthiophene)s with long side chains. ${ }^{11,12}$

In an effort to better understand the thermochromic properties of polythiophenes with different types of substitution patterns, we have prepared poly(3-docosoxy-4methylthiophene) (PDMT). On heating thin films of PDMT, the color of the polymer changes from purple to yellow. When the samples are rapidly quenched, a red-orange mesophase is generated. On heating a second time, the mesophase changes color irreversibly. This two-step thermochromism was investigated by reflection and fluorescence spectroscopies and differential scanning calorimetry (DSC). 


\section{Experimental}

\section{Materials}

All reagents were used without further purification. Reagents and solvents were purchased from either Sigma-Aldrich (St.Louis, MO) or Fisher Scientific (Rockford, IL). Synthesis of 3-Docosoxy-4-methylthiophene Twenty grams (61 mmol) of ndocosanol was added to a $500-\mathrm{mL}$ three-necked flask at $100{ }^{\circ} \mathrm{C}$. To this flask was added $2.0 \mathrm{~g}$ of $60 \% \mathrm{NaH}(50 \mathrm{mmol})$ under positive nitrogen pressure. The reaction mixture was stirred until the reaction with sodium hydride was complete. In a separate 100-mL flask, $4.5 \mathrm{~g}$ (25 mmol) of 3-bromo-4-methyl thiophene, $80 \mathrm{mg}(0.80 \mathrm{mmol})$ of $\mathrm{CuCl}, 70 \mathrm{mg}(0.74 \mathrm{mmol})$ of 2-aminopyridine, and diglyme $(15 \mathrm{~mL})$ were dissolved and transferred to the three-necked flask containing the alkoxide under positive nitrogen pressure using a cannula.13 The reaction mixture was stirred at $120{ }^{\circ} \mathrm{C}$ for 2 days followed by cooling to room temperature, extraction with methylene chloride, and filtration through celite. Column chromatography over silica gel in hexanes provides 3-docosoxy-4-methylthiophene $(6.0 \mathrm{~g}, 57 \%$ yield $)$ after rotary evaporation. 1H-NMR (300 MHz, CDCl3): d 6.84 (d, 1H), 6.15 (d, 1H), 3.96 (t, 2H), 2.13 (s, 3H), $1.82(\mathrm{~m}, 2 \mathrm{H}), 1.49$ (m, 2H), 1.31 (m 36H), 0.93 (t 3H). 13C-NMR (75 MHz, CDCl3): d 156.36, 129.00, 119.62, 95.78, 69.99, 32.10, 29.74, 29.36, 26.23, 22.72, 14.10, 12.53.

\section{Synthesis of PDMT}

Six grams (14 mmol) of 3-docosoxy-4-methylthiophene was added to a dry round bottom flask under N2. To this flaskvwas added $50 \mathrm{~mL}$ of methylene chloride. To this solution was added $4.0 \mathrm{~g}$ ( $25 \mathrm{mmol})$ of $\mathrm{FeCl} 3$ followed by stirring overnight. The 
reaction mixture was precipitated in methanol to obtain PDMT (2.1 g, 33\% yield) as a deep violet powder. 1H-NMR of PDMT (300 MHz, CDCl3): d 3.8 (m, 2H), 2.3 (s, $3 \mathrm{H}), 1.72(\mathrm{~m}, 2 \mathrm{H}), 1.56(\mathrm{~m}, 2 \mathrm{H}), 1.24(\mathrm{~m} \mathrm{36H}), 0.87(\mathrm{~m} \mathrm{3H})$. The molecular weight of the polymer, estimated by SEC, gave Mn and Mw values of 1.32 x 104 and $3.1 \times 104$, respectively.

\section{Measurements}

DSC thermograms were acquired on a TA Instruments Q100 instrument in aluminum pans at $10{ }^{\circ} \mathrm{C} / \mathrm{min}$ under flowing nitrogen atmosphere. The polymer sample was prepared for DSC by drip-coating a solution of the polymer in tetrahydrofuran (THF) onto aluminum foil and evaporating the solvent. The polymer film was heated with a heat gun and rapidly quenched with liquid nitrogen to form the mesophase. The polymer film was then scraped off the aluminum foil and transferred into a preweighed DSC aluminum pan. Reflection spectra were measured on an Ocean Optics S2000 instrument using a cylindrical fiber optics probe containing one source fiber and seven collecting fibers. The spectra were taken in reference to white background and dark background between 400 and $800 \mathrm{~nm}$ using a tungsten halogen lamp. Variable-temperature fluorescence spectra are recorded on Ocean Optics S2000 instrument with a blue LED light source $(\lambda=470 \mathrm{~nm})$. The polymer films for reflection and fluorescence spectroscopy were prepared by drip-coating the polymer solution in THF onto a piece of white paper and evaporating the solvent with a heat gun. The mesophase was generated by heating the paper containing the polymer film and rapidly cooling with a cold metal plate. The polymer film was placed on aluminum block containing the thermometer. 
The aluminum block was placed on a hot plate and heated at $2{ }^{\circ} \mathrm{C} / \mathrm{min}$. NMR spectra of monomer were recorded on a Bruker 300-MHz NMR spectrometer using CDCl3 as solvent. Molecular weight of the polymer was estimated by size exclusion chromatography in THF.

\section{Results and discussion}

Copper (I) chloride-catalyzed Ullmann coupling of 3-bromo - 4-methylthiophene with 1-docosanol was used to prepare 3-docosoxy-4-methylthiophene. Oxidative polymerization of 3-docosoxy-4-methylthiophene was afforded by addition of $\mathrm{FeCl}_{3}$ in methylene chloride followed by precipitation in methanol. PDMT was isolated as a deep violet powder. Thin films of PDMT are violet at room temperature and bright yellow at high temperature. The rapidly quenched film exhibits a red-orange color. The red-orange color is indefinitely stable at room temperature. On heating the rapidly quenched films, the red-orange color first changes to violet and then changes to yellow at high temperature. Related thermochromic responses have been observed for poly(3alkylthiophene)s with very long linear alkyl side chains (>C22) and is consistent with the formation of a mesophase on quenching. ${ }^{11,12}$ Variable-temperature reflectance spectra (Fig. 1) of a rapidly quenched PDMT film were acquired. The variabletemperature reflectance spectra of a PDMT film containing the mesophase film, percent reflection versus temperature, can be fit to a double sigmoidal function of the form

$$
F(R)=R_{0}+\frac{a_{1}}{1+e^{-\left(T-T_{1}\right) / \Delta T_{1}}}+\frac{a_{2}}{1+e^{-\left(T-T_{2}\right) / \Delta T_{2}}}
$$

Where $T_{1}$ and $T_{2}$ are the transition temperatures, $\Delta T_{1}$ and $\Delta T_{2}$ are the width of the transitions, $\mathrm{a}_{1}$ and $\mathrm{a}_{2}$ are the reflection changes through the transition, and $\mathrm{R}_{0}$ is the 
baseline reflection. The transition temperatures as determined from reflectance data at $600 \mathrm{~nm}$ are summarized in Table 1 . The reflection spectra of the mesophase are similar to the annealed ground-state phase, but the two low-temperature phases are quite different from the high-temperature phase. Related variable temperature fluorescence experiments were conducted on PDMT films containing the mesophase (Fig. 2). The fluorescence spectrum (excited at $470 \mathrm{~nm}$ ) of the mesophase contains a weak, broad emission with a maximum centered at $\sim 650 \mathrm{~nm}$. On heating, the emission intensity decreases at intermediate temperatures $\left(60-110^{\circ} \mathrm{C}\right)$, followed by an increase in intensity at high temperature $\left(>120{ }^{\circ} \mathrm{C}\right)$. The emission band of the high temperature phase has peaks at 540 and $565 \mathrm{~nm}$, with much greater intensity than the emission band of the mesophase. The temperature-dependent intensity of the emission spectra of a PDMT film containing the mesophase at $650 \mathrm{~nm}$ is provided in Figure 3. The transition temperatures as determined from fitting the emission data to eq 1 are similar to the transition temperatures determined from the reflection data (Table 1).The thermal behavior of the polymer was investigated by DSC. The DSC thermogram of the PDMT in the mesophase (Fig. 4) was conducted starting at $-10{ }^{\circ} \mathrm{C}$ and ramped at $10{ }^{\circ} \mathrm{C} / \mathrm{min}$ to $140{ }^{\circ} \mathrm{C}$. The first heating cycle contains three peaks. The first peak at $\sim 38{ }^{\circ} \mathrm{C}$ corresponds to a melt transition of the side chain, the second peak at $\sim 48{ }^{\circ} \mathrm{C}$ corresponds to the loss of the mesophase, and a high-temperature peak at $\sim 111{ }^{\circ} \mathrm{C}$ corresponds to the reversible thermochromic transition associated with mainchain melting. ${ }^{11,12}$ Unlike the alkyl analogues, PDMT does not show an unusual peak shape in the central transition, suggesting that the melting/recrystallization proposed for the poly(3-alkylthiophene)s does not occur in PDMT. After a slow cooling cycle to 
anneal to the polymer, the second heating cycle contains only two peaks. The absence of one transition is consistent with a loss of the mesophase on slow cooling. The two transitions are consistent with side chain melting and main chain melting. The DSC, reflection spectra, and emission spectra indicate the presence of a partially disordered mesophase of PDMT that is structurally and electronically different from the ordered annealed low-temperature phase and the high-temperature disordered phase. The mesophase is generated via rapid cooling of the high-temperature phase. All three techniques are in agreement regarding the transition temperatures: the lower transition from the mesophase to the annealed state occurs at $\sim 40{ }^{\circ} \mathrm{C}$, whereas the transition to the hightemperature phase occurs at $\sim 120{ }^{\circ} \mathrm{C}$. The different phases of PDMT have differing degrees of $\pi-\pi$ stacking and extended $\pi$ conjugation. The annealed lowtemperature phase has the most extended $\mathrm{p}$ conjugation as evidenced by the longest wavelength reflection spectrum and the greatest $\pi$ - $\pi$ stacking as evidenced by the weak fluorescence intensity. ${ }^{2}$ The hightemperature phase has little extended conjugation and weak $\pi-\pi$ stacking interactions as evidenced by the shortest wavelength reflection spectra and greatest intensity fluorescence spectra. The mesophase has an intermediate extent of conjugation and $\pi-\pi$ stacking. The spectral and thermal properties of PDMT are very similar to those previously reported for poly(3-docosylthiophene), suggesting similar mechanisms of thermochromism for poly(3-alkylthiophene)s and poly (3alkoxy-4-methylthiophene)s. ${ }^{11,12}$ A mechanism for the phase transitions is provided in Figure 5. 


\section{Conclusions}

PDMT was synthesized via oxidative polymerization. Variable-temperature reflection and fluorescence spectroscopy of thin films and DSC support a two-step thermochromic transition with a very similar mechanism to that reported for poly(3docosylthiophene)s.

The authors thank the College of the Environment and Life Sciences at the University of Rhode Island and the USDA Hatch Program for financial support of this research. The authors thank Prof. R. B. Grubbs, Stony Brook Univ., for assistance with SEC. 


\section{Referenences}

1. Conjugated Polymers: Theory, Synthesis, Properties, and Characterization; Skotheim, T. A.; Reynolds, J. R., Eds.; CRC Press: Boca Raton, FL, 2007.

2. Handbook of Oligo- and Polythiophenes; Fichou, D., Ed.; Wiley: New York, 1999.

3. Faïd, K.; Fre'chette, M.; Ranger, M.; Mazerolle, L.; Le'vesque, I.; Leclerc, M.; Chen, T.-A.; Rieke, R. D. Chem Mater 1995, 7, 1390-1396.

4. Yang, C.; Orfino, F. P.; Holdcroft, S. Macromolecules 1996, 29, 6510-6517.

5. Roux, C.; Bergeron, J.-Y.; Leclerc, M. Makromol Chem 1993, 194, 869-877.

6. Faïd, K.; Leclerc, M. J. Chem Soc Chem Commun 1993, 962.

7. Wang, Y.; Mills, A.; Euler, W. B.; Lucht, B. L. Chem Commun 2006, 20, $2121-2122$.

8. Garreau, S.; Leclerc, M.; Errien, N.; Louarn, G. Macromolecules 2003, 36, 692-697.

9. Prosa, T. J.; Winokur, M. J.; McCullough, R. D. Macromolecules 1996, 29, $3654-3656$.

10. Le Bouch, N.; Auger, M.; Leclerc, M. Macromol Chem Phys 2008, 209, $2455-2462$.

11. Wang, Y.; Archambault, N.; Marold, A.; Weng, L.; Lucht, B. L.; Euler, W. B. Macromolecules 2004, 37, 5415-5422.

12. Wang, Y.; Archambault, N.; Belcher, A.; Busse, D.; Damon, D.; Mills, A.; Riddle, A.; Samardjiev, I.; Lucht, B. L.; Euler, W. B. Macromolecules 2008, $41,7115-7121$. 
13. Fagan, P. J.; Hauptman, E.; Shapiro, R.; Casalnuovo, A. J. Am Chem Soc 2000, 122, 5043-5051. 


\begin{tabular}{|lccc|}
\hline Property & $\mathrm{T}_{\mathrm{sm}}\left({ }^{\circ} \mathrm{C}\right)$ & $\mathrm{T}_{1}\left({ }^{\circ} \mathrm{C}\right)$ & $\mathrm{T}_{2}\left({ }^{\circ} \mathrm{C}\right)$ \\
Reflection spectra & - & 43 & 111 \\
Fluorescence Spectra & - & 36 & 120 \\
DSC first heating cycle & 38 & 48 & 111 \\
DSC second heating cycle & 45 & - & 111 \\
\hline
\end{tabular}

Uncertainties are $\pm 3{ }^{\circ} \mathrm{C}$ for the spectroscopy measurements and $\pm 1{ }^{\circ} \mathrm{C}$ for the DSC measurements.

Table 5-1. Summary of measured properties. 


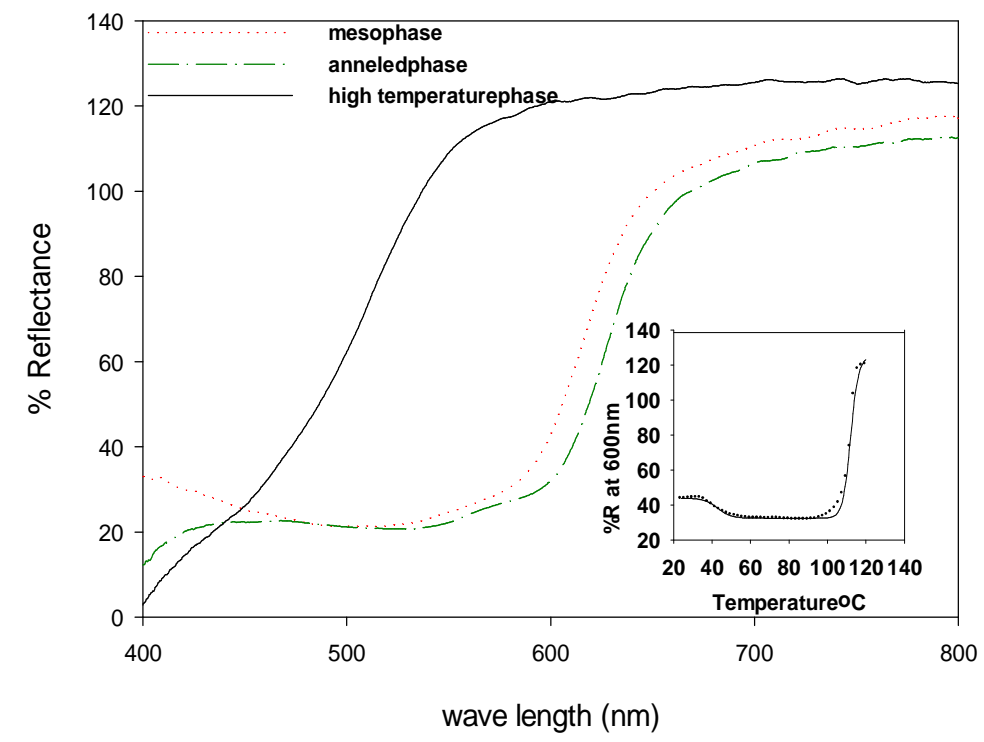

Figure 5-1. Reflectance spectra of poly(3-docosoxy-4-methylthiophene).

The inset shows the percent reflectance at $600 \mathrm{~nm}$ versus temperature for a sample starting with the mesophase heated at $2{ }^{\circ} \mathrm{C} / \mathrm{min}$. 


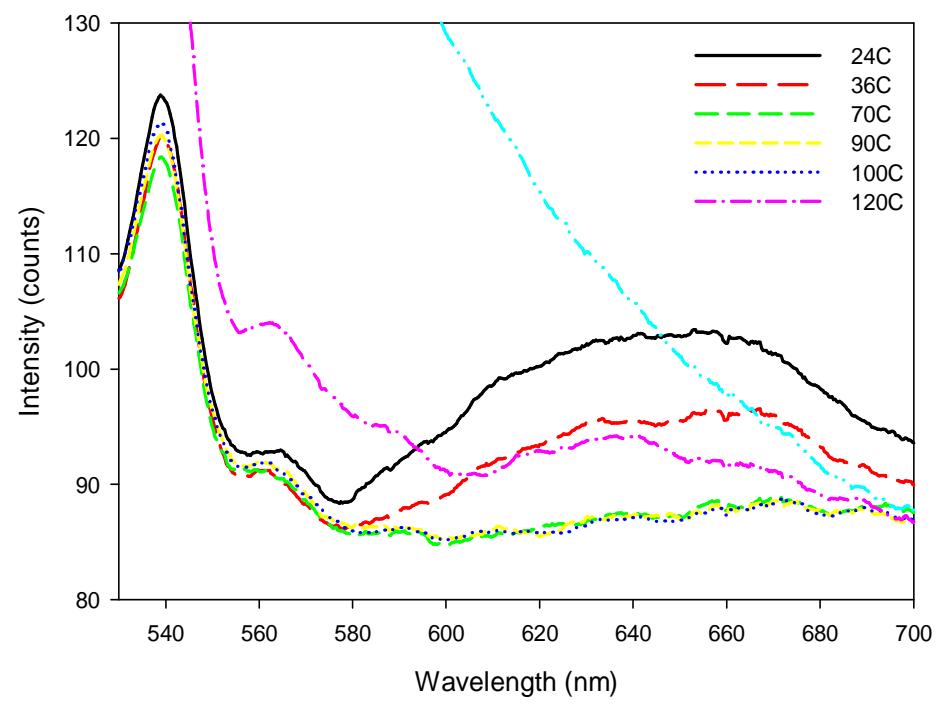

Figure 5-2. Emission intensity at $650 \mathrm{~nm}$ as a function of temperature. 


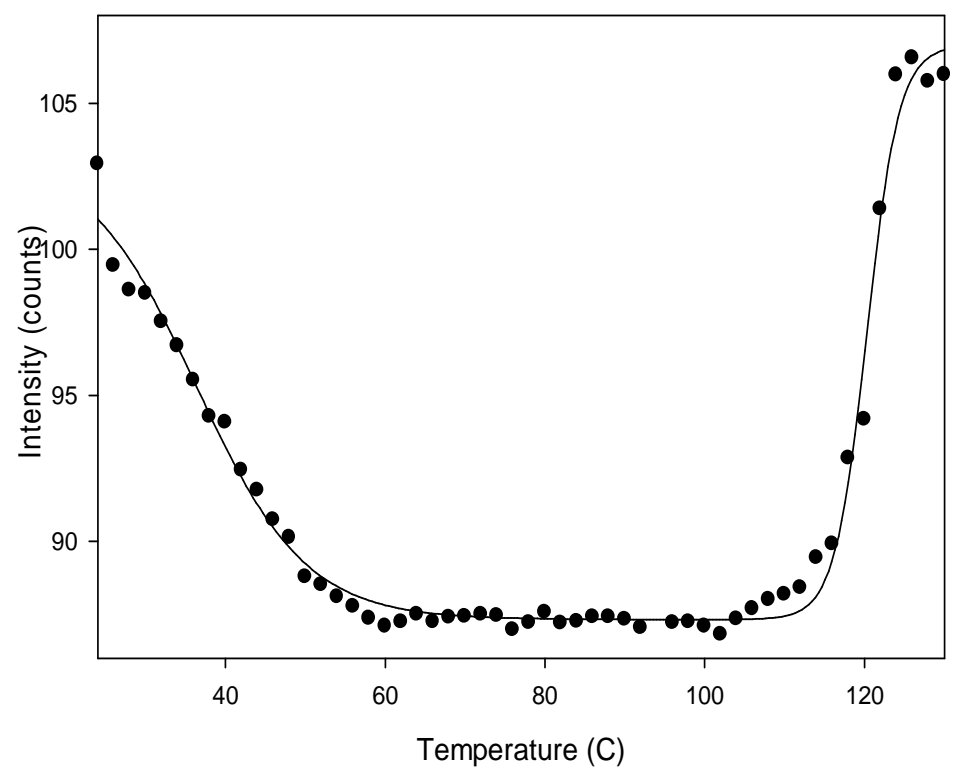

Figure 5-3. Emission intensity at $650 \mathrm{~nm}$ as a function of temperature. 


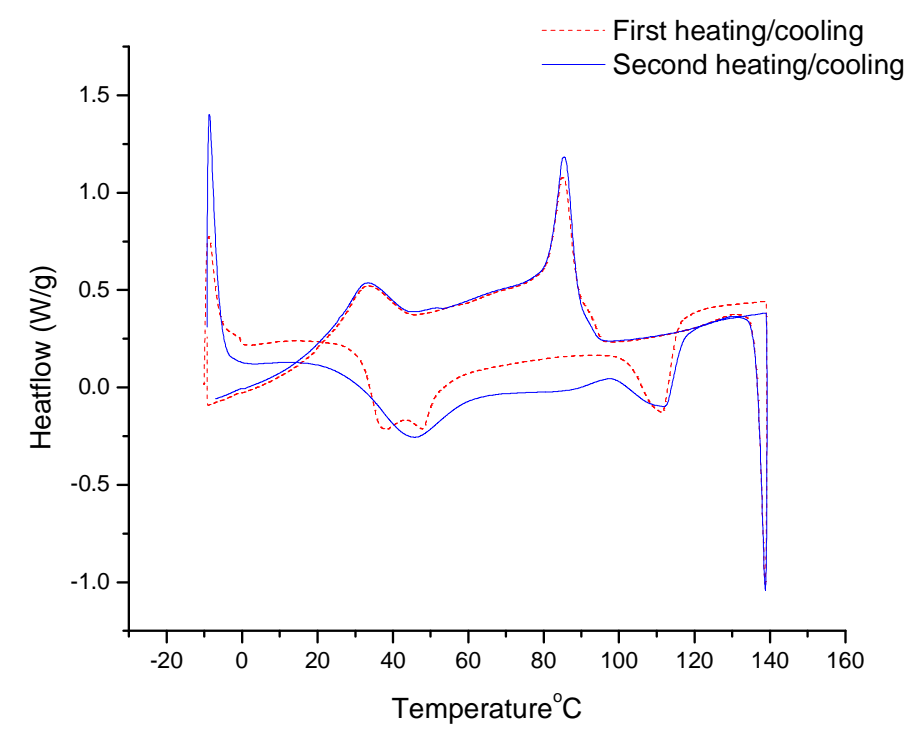

Figure 5-4. DSC thermogram of poly(3-docosoxy-4-methylthiophene) of sample containing mesophase (red dashed line, first heating/cooling cycle) and with no mesophase (blue, solid line). 


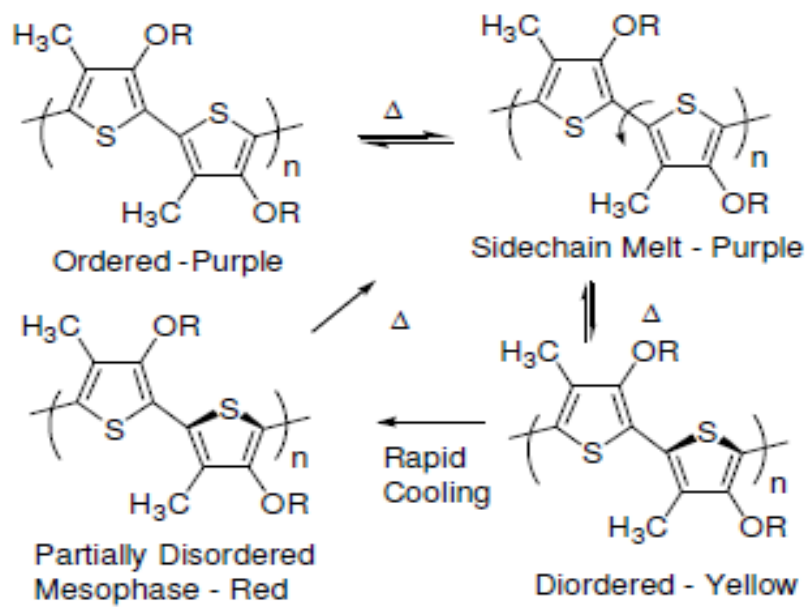

Figure 5-5. Proposed mechanism for the two-step thermochromic transition for poly(3-docosoxy-4-methylthiophene). 